\title{
MEASUREMENT OF SURFACE AREA \\ OF URANIUM DIOXIDE POWDER \\ AND SINTERED PELLETS
}

By

T. SMITH

\section{ATOMICS INTERNATIONAL}
A DIVISION OF NORTH AMERICAN AVIATION, INC.
P.O. BOX 309
CANOGA PARK, CALIFORNIA

This document is

CONTRACT: AT(11-1)-GEN-8

ISSUED: OCTOBER 1, 1960 


\section{DISCLAIMER}

This report was prepared as an account of work sponsored by an agency of the United States Government. Neither the United States Government nor any agency Thereof, nor any of their employees, makes any warranty, express or implied, or assumes any legal liability or responsibility for the accuracy, completeness, or usefulness of any information, apparatus, product, or process disclosed, or represents that its use would not infringe privately owned rights. Reference herein to any specific commercial product, process, or service by trade name, trademark, manufacturer, or otherwise does not necessarily constitute or imply its endorsement, recommendation, or favoring by the United States Government or any agency thereof. The views and opinions of authors expressed herein do not necessarily state or reflect those of the United States Government or any agency thereof. 


\section{DISCLAIMER}

Portions of this document may be illegible in electronic image products. Images are produced from the best available original document. 


\section{DISTRIBUTION}

This report has been distributed according to the category "Metallurgy and Ceramics" as given in "Standard Distribution Lists for Unclassified Scientific and Technical Reports" TID-4500 (15th Ed.), August 1, 1959. A total of 600 copies were printed.

\section{ACKNOWLEDGMENT}

The author wishes to acknowledge the help of Dr. Rex Shudde, who wrote the program in Fortran language for the IBM computor; and Mary Shideler, who operated the BET apparatus for some of the experiments. 


\section{CONTENTS}

Page

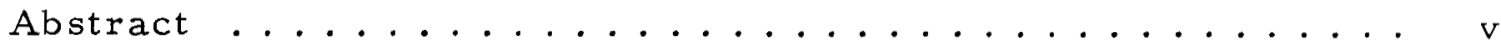

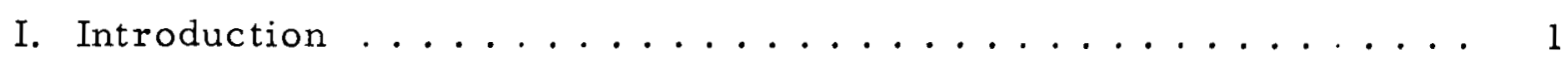

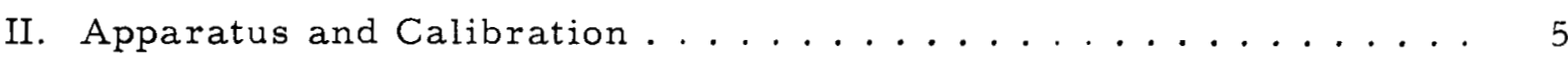

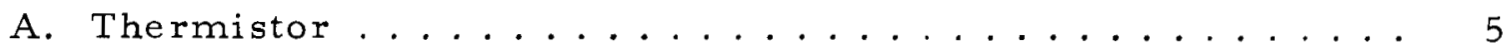

B. Thermistor Calibration ................. 10

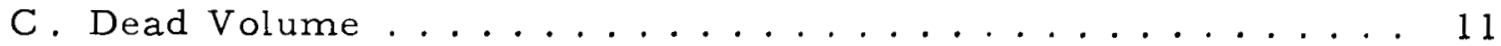

III. Procedure for a Surface Area Measurement . . . . . . . . . 13

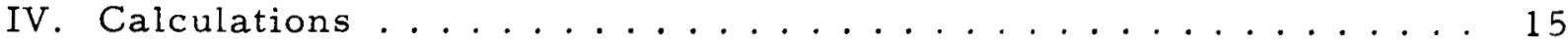

V. IBM 709 Computer Program ................ 18

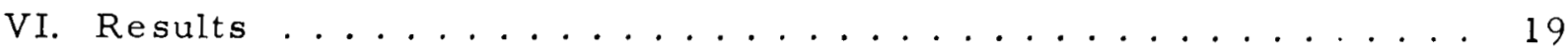

A. Surface Area Measurements ................ 21

B. Surface Area of Dummy Quartz Sample Holders . . . . . . . . 27

C. Surface Area of $\mathrm{UO}_{2}$ Pellets, Used to Correlate Oxidation

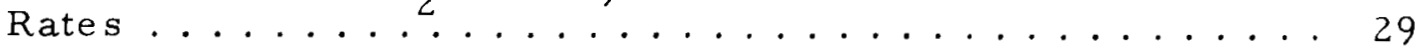

VII. Summary and Conclusions ................... 31

Appendixes

I. Method for Determination of Volume Available to Gas in Sample Holders ....................... 32

II. Effect of Experimental Errors on Surface Area

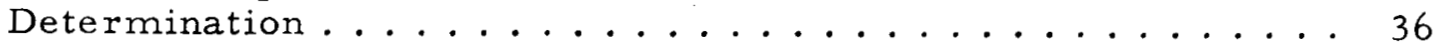

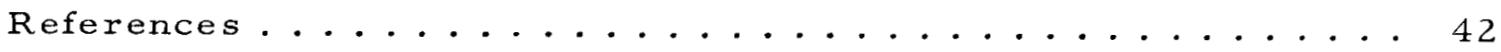

\section{TABLES}

I. Calibration Data for Glass Burette . . . . . . . . . . . 7

II. Dead Volume Determination.................... 12

III. BET Surface Area Measurements of Various Materials . . . . . . 22

IV. Correlation of Surface Area vs Average Diameter . . . . . . 25

V. Determination of Surface Areas of Dummy Quartz Sample

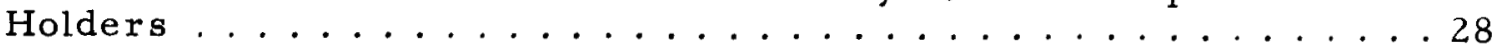

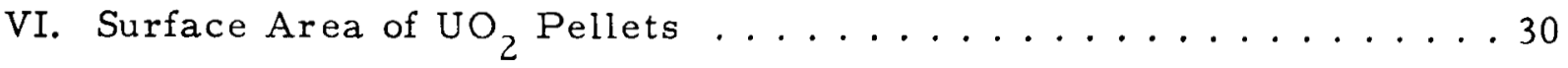

VII. Volume of Quartz Sample Holders................. 35

VIII. Effect of Errors on Calculated Surface Area . . . . . . . . . 37

N.AA-SR - 5319 


\section{FIGURES}

Page

1. Schematic of BET Surface Area Apparatus (7522-4347) . . . . . 5

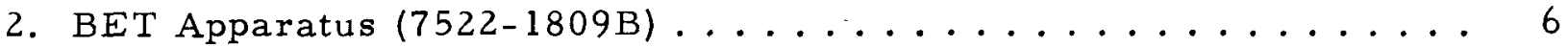

3. Glass Burette and Sample Holder of BET Apparatus

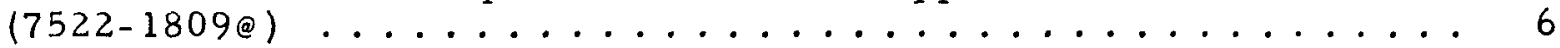

4. Effect of Ambient Temperature on Thermistor Resistance

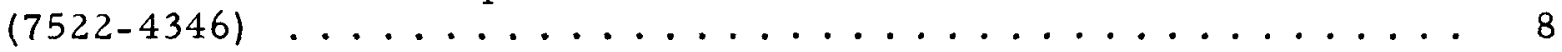

5. Change of Thermistor Characteristics with Time (7522-4345) . . . 9

6. Quartz Sample Holders (7522-1809@) ................13

7. Krypton Adsorption Isotherm on 50-mg Sample (E) of $\mathrm{UO}_{2}$ Powder $(7522-4344) \ldots \ldots \ldots \ldots 19$

8. Krypton Adsorption Isotherm on Sintered UO Pellet (G-2-C-11, Wet Density $93.6 \%$ TD), Showing Hysteresis on Desorption $(7522-4342)$

9. Time for Adsorption to Attain Equilibrium (Pellet G-2-C-11) (7522-4350).

10. BET Plots of $\frac{P \times 10^{-18}}{\left(P_{0}-P\right) N}$ vs $\frac{P}{P_{0}}$ for $\mathrm{UO}_{2}$ Powders of Various

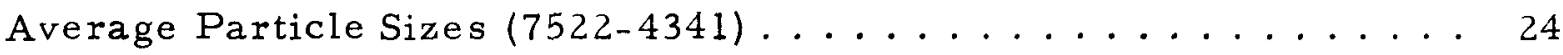

11. Correlation between Surface Area and Average Particle Diameter

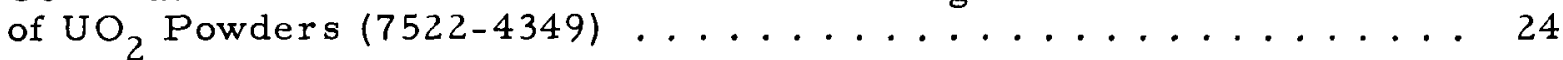

12. Log-Log Plot of Specific Surface Area vs Average Particle Diameter of $\mathrm{UO}_{2}$ Powders $(7522-4343) \ldots \ldots \ldots \ldots$

13. Surface Area Measuring Device (7522-4339) . . . . . . . . . 32

14. Example Application of IBM Program for Measurement of Surface Area of Sintered UO $\mathrm{U}_{2}$ Pellet (G-5-C-12) ......... 38

15. Photographs of Data on Cathode-Ray Tube

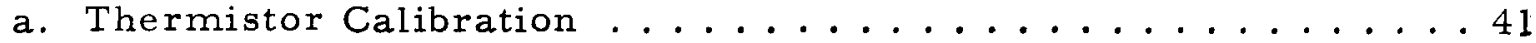

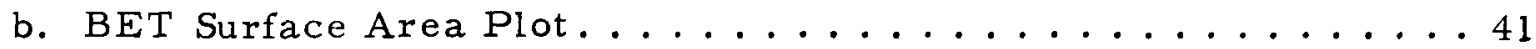




\begin{abstract}
The surface areas of sintered uranium dioxide pellets (individual pellets ranging from 50 to $2000 \mathrm{~cm}^{2}$ ) were measured with a precision of $1.3 \%$ and a reproducibility of about $4 \%$ with a BET adsorption apparatus, using krypton as the adsorbate.

Powder samples (10 to $50 \mathrm{mg}$ ) of uranium dioxide, anatase, zirconia, and ceria were measured with a precision of $0.5 \%$ and a reproducibility of about $3 \%$. An excellent correlation was found between the surface area and the average particle diameter, as measured with a Fisher Sub-Sieve Sizer. An equation, relating the surface area $(S)$ and the average particle diameter $(D)[S=1.67 / D$, as compared to $S=0.547 / D$ (if the particles were spherical)] shows the powder has a shape factor of about 3 .
\end{abstract}




\section{INTRODUCTION}

A process for pulverizing uranium dioxide sintered pellets by oxidationreduction cycling, as a step in the reprocessing and refabrication of spent nuclear reactor fuel, has been developed. ${ }^{1}$ The kinetics and mechanism of the oxidation reactions have been studied in detail, for sintered uranium dioxide pellets (93 to 99\% TD) and for sintered uranium dioxide pellets that contained various concentrations of fission-product oxides (fissia).

In kinetic studies, the rate of reaction is usually proportional to the solid surface area; and, for a theoretical interpretation of experimental reaction rates, in terms of statistical mechanics, or an absolute reaction rate theory, a knowledge of the true surface area is important.

It has been reported ${ }^{2}$ that the process of sintering can be followed or predicted on the basis of four parameters: genus, number, volume, and surface area. It is believed that it is possible to correlate such properties as density, strength, ductility, permeability, and various compacting and sintering controls, by expressing them in terms of these parameters. It was emphasized that different laboratories should specify, (a) the number of particles per unit mass, and (b) the surface area per unit mass, for any powder metallurgical operation, these being the most important variables.

It was therefore desirable to measure the surface area of uranium dioxide powders (that had undergone various oxidation-reduction cycles) which were to be fabricated to sintered pellets, and correlate the surface area with particle size, if possible. For the se reasons, an apparatus for measuring the surface area (10 to $1000 \mathrm{~cm}^{2}$ ) of sintered pellets was needed.

In 1939, Brunauer, Emmett, and Teller ${ }^{3}$ derived the equation:

$$
\frac{X}{V(1-X)}=\frac{1}{V_{m} C}+\frac{(C-1) X}{V_{m} C},
$$

where

$$
X=\text { relative pressure, } P / P_{o} \text {, for the adsorbate, }
$$


$V=$ volume of gas (STP) adsorbed at relative pressure $X$,

$V_{m}=$ volume of adsorbate required to form a monolayer on the surface of the adsorbent,

$C=$ a constant, given by the equation

$$
C=\frac{a_{1} b_{2}}{a_{2} b_{1}} e^{\left(E_{1}-E_{L}\right) / R T} .
$$

The coefficient of the exponential is considered to be approximately unity;

$$
\begin{aligned}
E_{1} & =\text { heat of adsorption in the first layer }, \\
E_{L} & =\text { heat of Iiquifaction of the adsorbate, } \\
R & =\text { the gas constant, } \\
T & =\text { absolute temperature, }
\end{aligned}
$$

$a$ and $b=$ constants.

Equation 1 has become very useful for interpreting multilayer gas adsorption isotherms, and has proved successful in the measurement of the surface area of solid catalysts. Until 1943, however, at least a square meter of surface was needed to make a BET measurement of any accuracy; and nitrogen, at $-195^{\circ} \mathrm{C}$, was usually the absorbate. In 1943, Wooten and Brown measured the surface area of the oxides from radio tube filaments when the total sample had an area of about $100 \mathrm{~cm}^{2}$. They used ethane and ethylene at $-195^{\circ} \mathrm{C}$ and claimed about $10 \%$ accuracy. In 1950 and 1953, Rhodin ${ }^{5,6}$ measured the surface area (as low as $10 \mathrm{~cm}^{2}$ ) of single crystals, using a microgravimetric technique. This technique has the disadvantage that very small samples must be used.

The technique developed and used for measuring the surface area of sintered uranium dioxide pellets and uranium dioxide powders in this report is similar to that reported by Rosenberg ${ }^{7}$ in 1956 . He used krypton at $-195^{\circ} \mathrm{C}$, and was able to measure the area of coarse germanium powders (as low as $50 \mathrm{~cm}^{2}$ ) to $1 \%$.

There are many other techniques for measuring surface areas, but they usually are not suitable for measuring small surface areas. An excellent review and discussion on the various methods of measuring the surface area of powders is given by Emmett. ${ }^{8}$ 
To measure small areas, it is preferable to use an adsorbate (krypton at $-195^{\circ} \mathrm{C}^{9}$ butane at $-78^{\circ} \mathrm{C}^{10}$ ) with a vapor pressure so small that the number of molecules left in the gas phase during the measurements is of the same order as the number that are adsorbed.

It is demonstrated, in this report, that surface areas can be measured to a precision of $\pm 5 \mathrm{~cm}^{2}$. Repeated experiments on the same sample gave reproducible surface areas to within $5 \%$. 


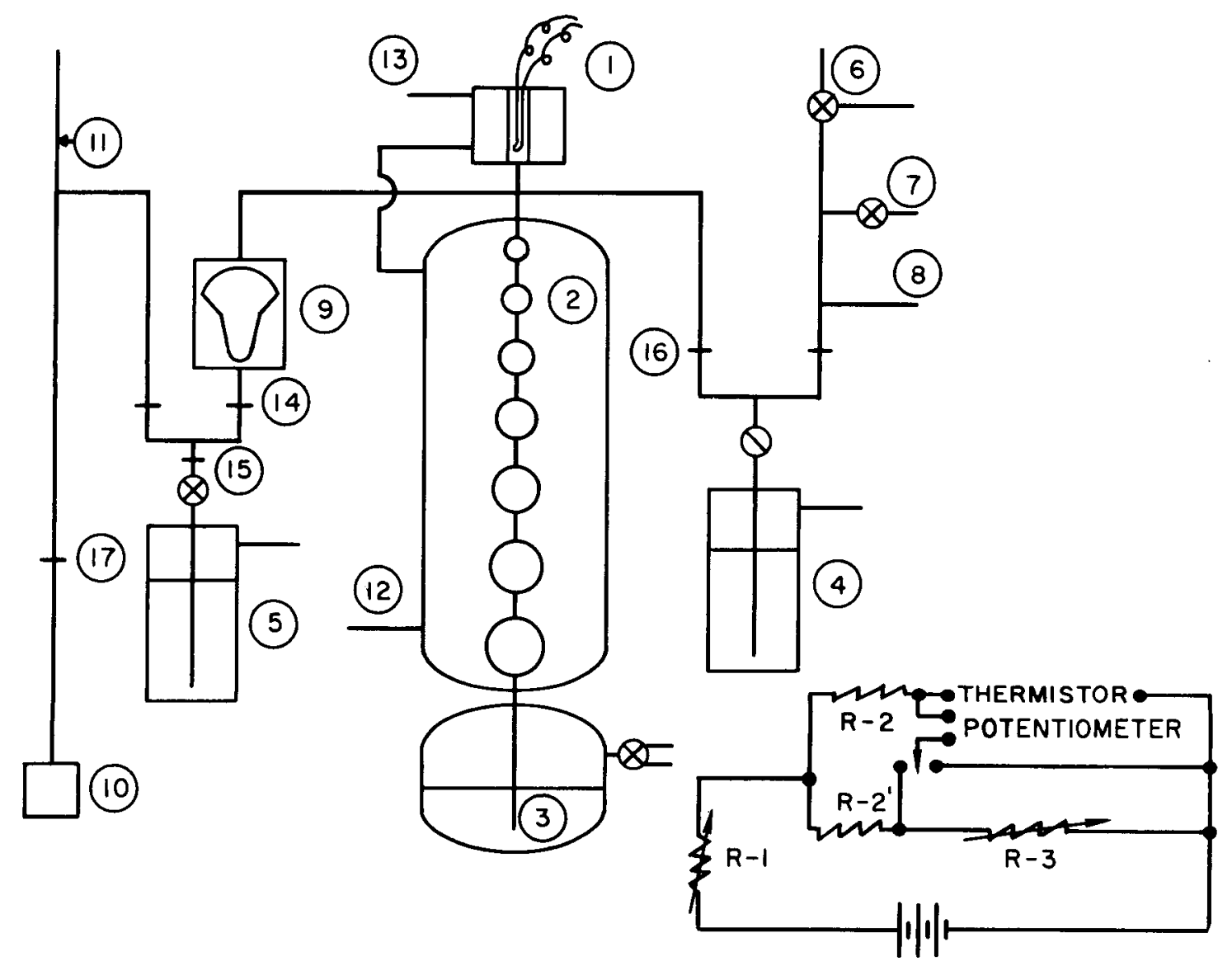

1. WATER JACKETED THERMISTOR

2. WATER JACKETED COLUMN OF CALIBRATED VOLUMES

3. MERCURY RESERVOIR FOR GAS DISPLACEMENT

4. MERCURY CUT OFF VALVE TO VACUUM PUMPS

5. MERCURY CUT OFF VALVE TO SAMPLE

6. THREE WAY STOP COCK

7. NEEDLE VALVE

8. TO THE MC LEOD GAUGE

9. MERCURY FLOAT VALVE

10. SAMPLE HOLDER

11. CAPILLARY TUBE

12. INLET FOR CONSTANT TEMPERATURE WATER

13. OUTLET FOR CONSTANT TEMPERATURE WATER

R-I VARIABLE DECADE RESISTOR

$R-21000 \sim$ RESISTOR

$R-2$ ' $1000 \sim$ RESISTOR

R-3 VARIABLE DECADE RESISTOR

Figure 1. Schematic of BET Surface Area Apparatus 


\section{APPARATUS AND CALIBRATION}

A schematic diagram of the apparatus is shown in Figure 1, photographs are given in Figures 2 and 3. The column of bulbs (Item 2, Figure 1) was calibrated by weighing mercury removed from the bulbs (between lines etched on the capillary tube between bulbs). Table I gives the results of this calibration. The volumes were accurate to approximately $0.002 \mathrm{ml}$, or $\pm 0.014 \%$, for the largest bulb $(72.119 \pm 0.001 \mathrm{ml})$ and $\pm 0.095 \%$, for the smallest bulb $(1.9018 \pm 0.0018 \mathrm{ml})$. Bulb No. 1 is the top bulb, No. 2 the next to the top, and so on to No. 7. Bulb No. 7 was not calibrated.

\section{A. THERMIST OR}

To measure small areas by the BET method, it is ncessary to measure the pressure of the adsorbate gas to high precision and reproducibility, without involving a large dead volume for the pressure sensing device. A Thermistor is particularly useful because of its high sensitivity and because it can be placed in a very small dead volume.

A Thermistor is a small semiconducting oxide bead which has an electrical resistance that falls off exponentially with rising temperature. If a current is passed through the bead, it will heat up and its resistance will drop. The temperature of the Thermistor will become constant when a steady state exists between the heat input and the heat transfer away from the bead. Since heat transfer is very sensitive to the gas pressure at low pressures $\left(10^{-4}\right.$ to $\left.3 \mathrm{~mm} \mathrm{Hg}\right)$, it is possible to calibrate the Thermistor with resistance as a function of pressure.

The circuit in Figure 1 is a simple wheatstone bridge arrangement, with the Thermistor as one leg of the bridge. In Figure $1, R_{1}$ is a precision variable resistance (right hand decade box in Figure 2), $R_{2}$ and $R_{2}^{\prime}$ are $1000 \Omega$ wire-wound resistances, and $R_{3}$ is another precision variable resistance (left hand decade box, Figure 2). The Thermistor (Type GA 45J1, obtained from Fenwal Electronics Inc.) had a resistance, at atmospheric pressure and room temperature, of 45,000 $\Omega$, and had a dissipation constant of 0.7 . The Thermistor used by Rosenberg ${ }^{7}$ (L252-A) had a 40,000 $\Omega$ resistance, but only a 0.1 dissipation constant. As a consequence, he was able to operate with a partially discharged lead storage battery, whereas the Thermistor used here needed more power, two 12-volt batteries in series.

NAA-SR -5319 


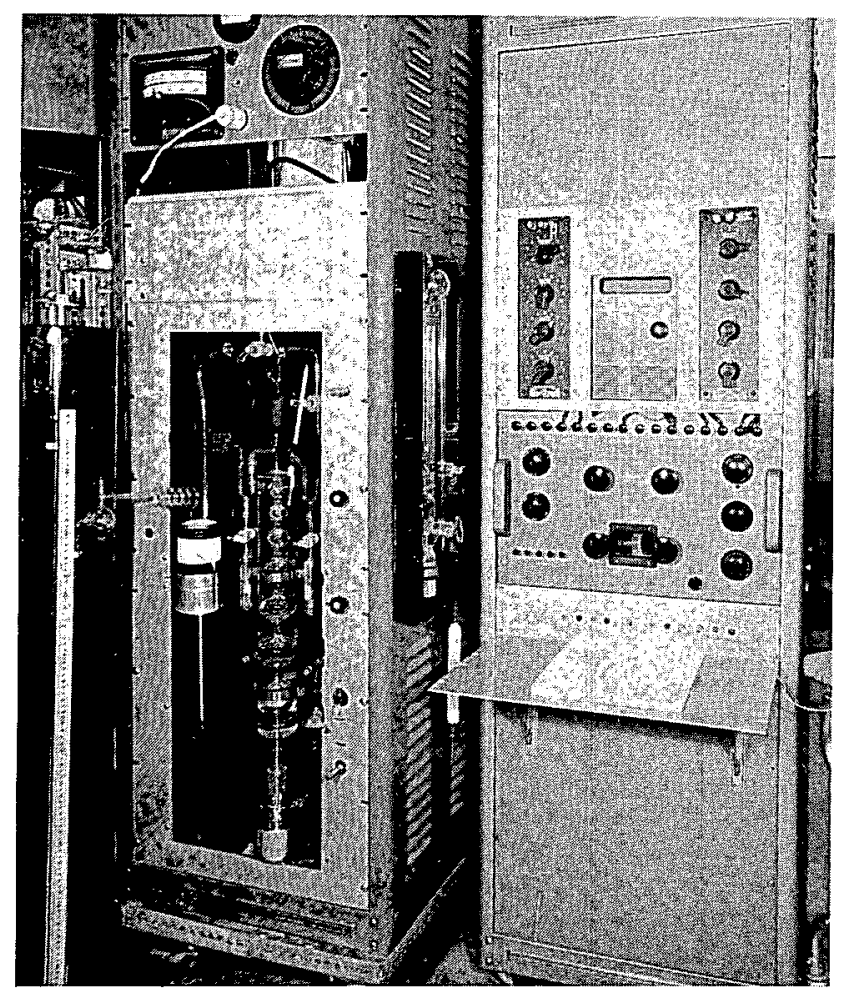

Figure 2. BET Apparatus

Figure 3. Glass Burette and Sample Holder of BET Apparatus

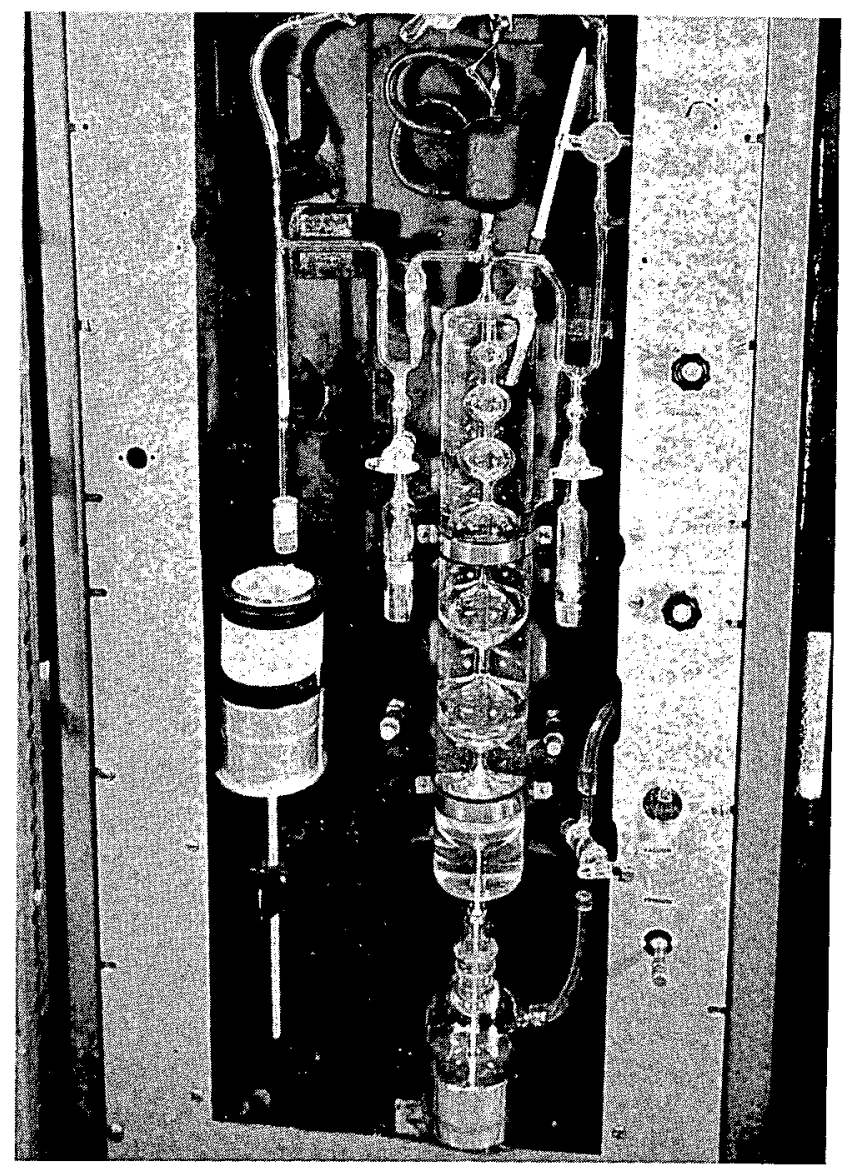


TABLE I

CALIBRATION DATA FOR GLASS BURETTE

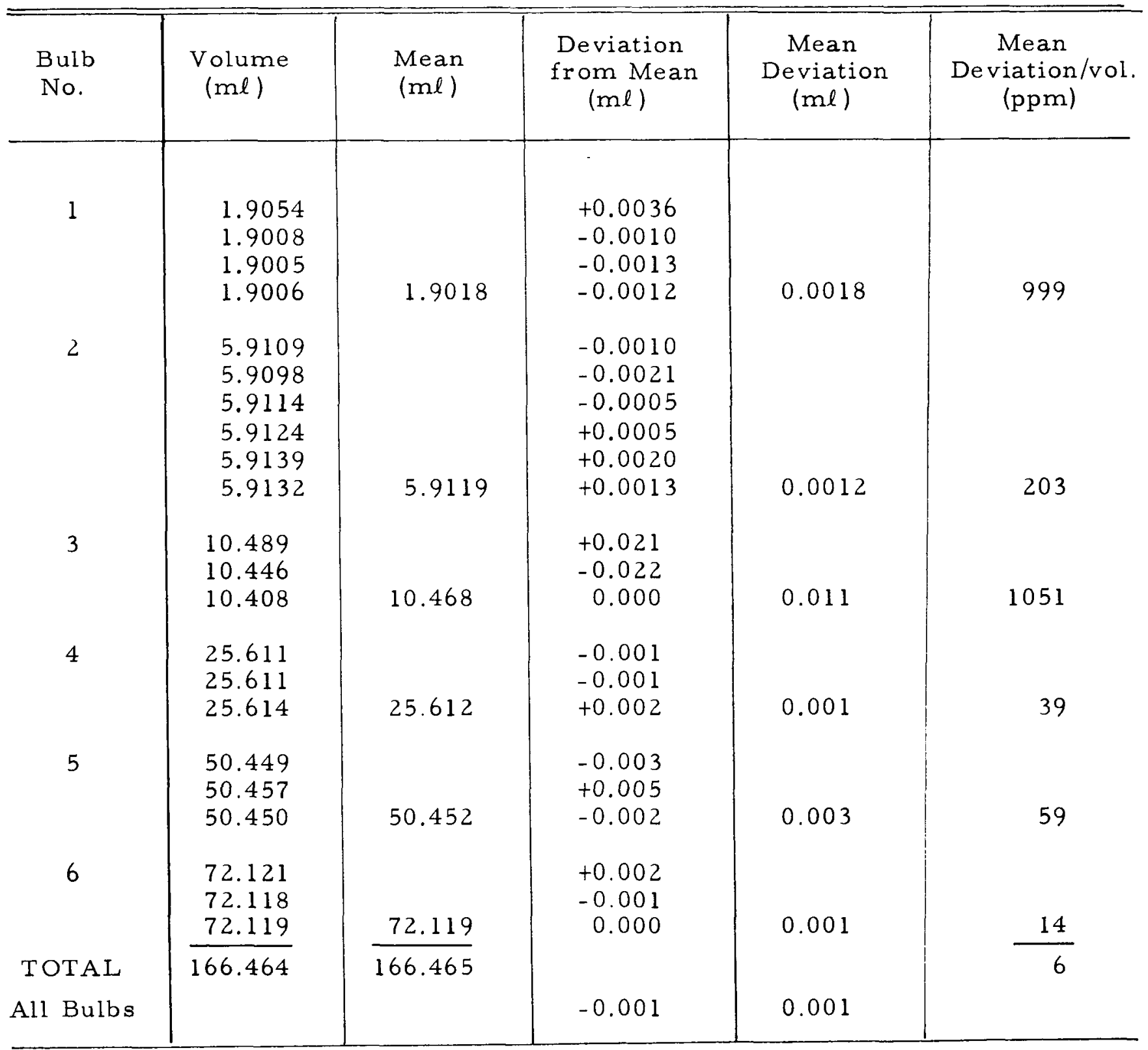


A Leads Northrop (Type K-3) universal potentiometer, in conjunction with a galvanometer (Figure 2), was connected with a switch, so that the potential across the Thermistor $\left(V_{T h}\right)$ or that across the bridge $\left(V_{o f f}\right)$ could be measured. To operate the Thermistor, $R_{1}$ was first set to $1000 \Omega, R_{3}$ was set between 50 and $100 \Omega$, and the potentiometer was switched to read $V_{o f f}$. The resistance $R_{1}$ was decreased until the potential across the bridge was zero, at which point the resistance of the Thermistor is just that of $R_{3}$.

Under operating conditions (with $R_{1}$ and $R_{3}$ set), five variables can change the potential across the bridge: gas pressure, ambient temperature around the Thermistor, change in the battery voltage, change in the Thermistor characteristics, and light.

In order to zero the instrument, so that a change in $V_{\text {off }}$ would be due only to pressure change, and so that the same value for $V_{\text {off }}$ represented the same pressure, some known reference pressure must be used. The most reproducible and

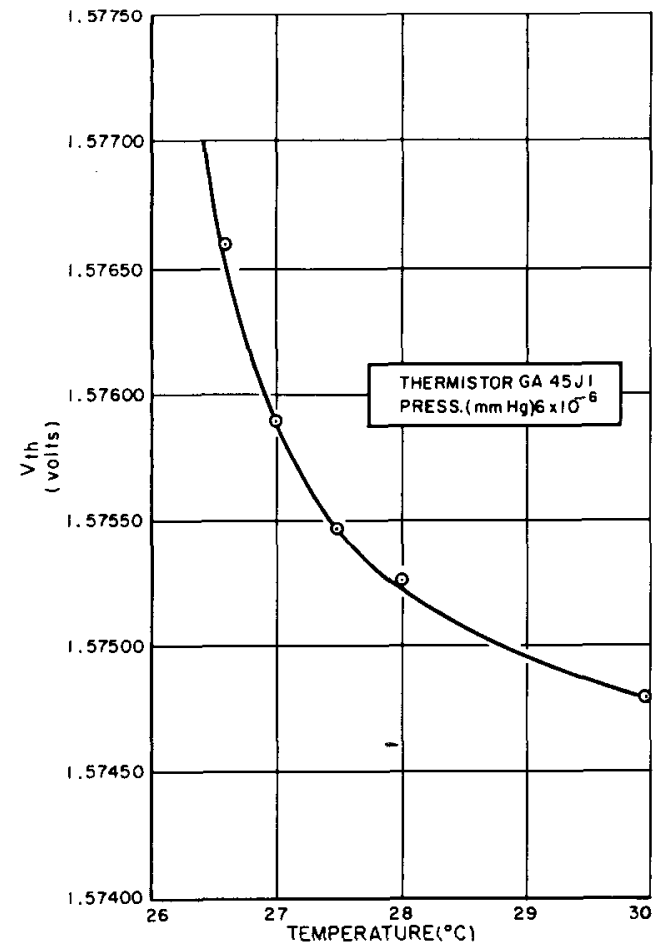

Figure 4. Effect of Ambient Temperature on Thermistor Resistance accurate pressure for this was zero pressure $\left(<10^{-5} \mathrm{~mm} \mathrm{Hg}\right)$.

Each time the Thermistor was calibrated, the system was evacuated to less than $10^{-5} \mathrm{~mm} \mathrm{Hg}$ (below which the Thermistor is very insensitive to pressure changes).

Figure 4 shows the effect of ambient temperature on the Thermistor (approximately $2.50 \mathrm{mv} /{ }^{\circ} \mathrm{C}$ at $26.5^{\circ} \mathrm{C}$ ). The calibrated column of bulbs and the Thermistor were jacketed with constant temperature water which flowed from a constant temperature bath circulating system (Harshaw Cat. No. H56585Type B), in at Point 12 of Figure 1 and out at Point 13 of Figure 1, back to the bath. The temperature held constant to $\pm 0.02^{\circ} \mathrm{C}$, so that an error of not more than $\pm 0.02 \mu$ was due to ambient temperature fluctuation (maximum Thermistor sensitivity was $2 \mathrm{mv} / \mu$ ). 
A change in battery voltage could be adjusted for, by changing $R_{1}$, and the bulb that held the Thermistor was painted black to prevent any effect from photons. Then, the only variable that would interfere was a drift in the Thermistor characteristics. Rosenberg ${ }^{7}$ states that his Thermistor was very stable, after two or three days of operation; and that, once he calibrated his Thermistor as a function of pressure, it was not necessary to do it again.

Unfortunately, the Thermistor used in this work was not stable, and checking two other Thermistors gave the same problem.

Two important problems were confronted with the system: (1) the tendency to slowly drift in one direction, from day to day, and (2) the erratic short-time fluctuations, during an experiment.

The erratic short-time fluctuations were due to the batteries. By replacing the Thermistor in the circuit with a precision resistance, it was found that the circuit was completely stable for long periods of time, which proved that the slow drift was due to changing characteristics of the Thermistor itself.

Figure 5 shows a record of the Thermistor characteristics, over a period of 160 days. A relationship between $R_{1}, V_{o f f}, V_{T h}$, and the battery voltage

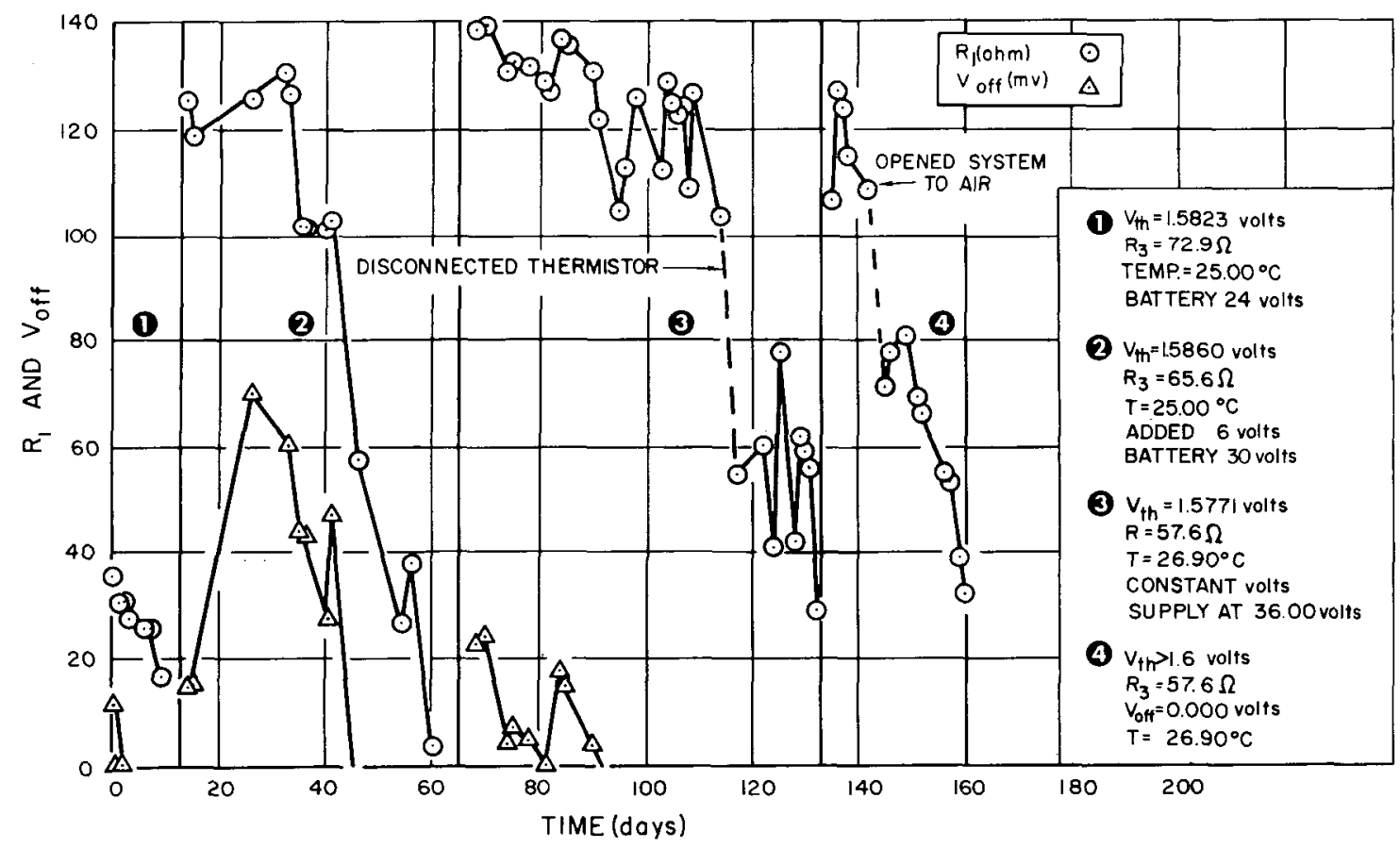

Figure 5. Change of Thermistor Characteristics with Time 
$\left(V_{B}\right)$ is:

$$
R_{1}=V_{o f f} / I+V_{B} / I+V_{T h}\left(R_{2}^{\prime}+R_{3}\right) / I
$$

where

$$
I=\text { current passing through } R_{1} \text {. }
$$

It is seen, from Equation 3, that if $V_{T h}$ is held constant and $V_{B}$ changes only slightly, $R_{1}$ is proportional to $V_{\text {off }}$, as seen in Figure 5.

It is believed that, during Period 2 of Figure 5, $R$, had to be adjusted because of a change in the battery voltage and the Thermistor resistance. At 68 days, the batteries were disconnected and replaced with a constant voltage supply (the voltage was set at $36 \mathrm{v}$ ) which eliminated erratic pulsating fluctuations in $V_{\text {off }}$ during an experiment.

The Thermistor changes characteristics dramatically, with a sudden change in input voltage, mechanical shock, or sudden large pressure change.

\section{B. THERMISTOR CALIBRATION}

The instability of the Thermistor made it necessary to calibrate each day as follows:

1) After zeroing the apparatus, Valves 5 and 6 were closed, and a sample of krypton was let into the system through the Needle Valve (Item 7, Figure 1).

2) The McLeod gauge was used to measure the pressure at various mercury levels, at the same time recording the value of $V_{\text {off }}$ at each level, as a rough check. An accurate calibration could not be made with the McLeod gauge, because it was only reproducible to $5 \%$, and the volume change in making the McLeod reading was large enough to make a significant pressure change during a measurement.

A precise internal calibration was made as follows:

1) The apparatus was zeroed, a krypton sample was let in to about $10 \mu$, as read by the McLeod gauge, then the mercury cut-off valve (Item 4, Figure 1) was closed. 
2) The mercury from Item 3 Figure 1 was raised, from bulb to bulb, and the value of $V_{\text {off }}$ measured for each bulb.

3) Starting with the initial McLeod reading as a reference point, a precise value of the pressure could be calculated with the perfect gas law, since the bulb volumes were known to better than $0.1 \%$.

Only one McLeod reading was needed as a reference for the entire calibration. It was necessary to adjust the gas pressure with Needle Valve 7

(Figure l) to a $V_{\text {off }}$ value identical with a.previous value, each time a new sample of gas was let in to raise the pressure. This was not too difficult to do, as very fine control could be obtained with the Needle Valve.

\section{DEAD VOLUME}

If the mercury in Valve 5 (Figure 1) is raised to Point 14, and that in Valve 4 is raised to Point 16, the unknown dead volume $\left(V_{d}\right)$ is that in the capillary tube, in Valve 9, and around the Thermistor. A value for $V_{d}$ can be obtained from the equation:

$$
V_{d}=\frac{P_{1} V_{1}-P_{2} V_{2}}{P_{2}-P_{1}}
$$

where the $V$ 's are the known volumes in the calibrated column of bulbs. Table II gives the values for the pressure at various bulb settings (i.e., bulb settings 0 , 1,2 , and 3 represent a total known volume of $0,1.902,7.814$, and $18.282 \mathrm{~cm}^{3}$ respectively, as can be seen from Table I). There are $n(n-1) / 2$ combinations for Equation 2, if $n$ measurements were made. The six calculated values of $V_{d}$, and the standard deviation for these, are given in Table II. The average value for $V_{d}$ is $6.340 \pm 0.018 \mathrm{~cm}^{3}$. 
TABLE II

DEAD VOLUME DETERMINATION

\begin{tabular}{|c|c|c|c|c|c|}
\hline \multirow{2}{*}{ Bulb } & \multirow{2}{*}{$\begin{array}{l}\mathrm{P} \\
(\mu)\end{array}$} & \multirow{2}{*}{$\begin{array}{c}V-V_{d} \\
\left(\mathrm{~cm}^{3}\right)\end{array}$} & \multirow{2}{*}{$P\left(V-V_{d}\right)$} & \multicolumn{2}{|c|}{ Calculated Values } \\
\hline & & & & $\begin{array}{c}V_{d} \\
\left(\mathrm{~cm}^{3}\right)\end{array}$ & $\begin{array}{l}\text { Standard } \\
\text { Deviation }\end{array}$ \\
\hline 0 & 950.5 & 0 & 0 & 6.361 & 0.021 \\
\hline 1 & 731.7 & 1.902 & 1392 & 6.330 & 0.010 \\
\hline 2 & 425.4 & 7.814 & 3324 & 6.341 & 0.001 \\
\hline \multirow[t]{4}{*}{3} & 244.8 & 18.282 & 4475 & 6.307 & 0.033 \\
\hline & & & & 6.331 & 0.009 \\
\hline & & & & 6.373 & 0.033 \\
\hline & & & Average & 6.340 & 0.018 \\
\hline
\end{tabular}




\section{PROCEDURE FOR A SURFACE AREA MEASUREMENT}

To replace a sample without interfering with the vacuum system, the mercury in Valve 5 (Figure 1) was allowed to rise until Float Valve 9 closed. The 2-mm capillary tube between Points 11 and 10, Figure 1, was broken to remove the sample from the previous experiment. Next, the $0.5-\mathrm{mm}$ capillary tube (Figure 1) was broken, so that a new sample (Note Figure 6) could be placed in the system by glass blowing. After the new sample was on, a vacuum was

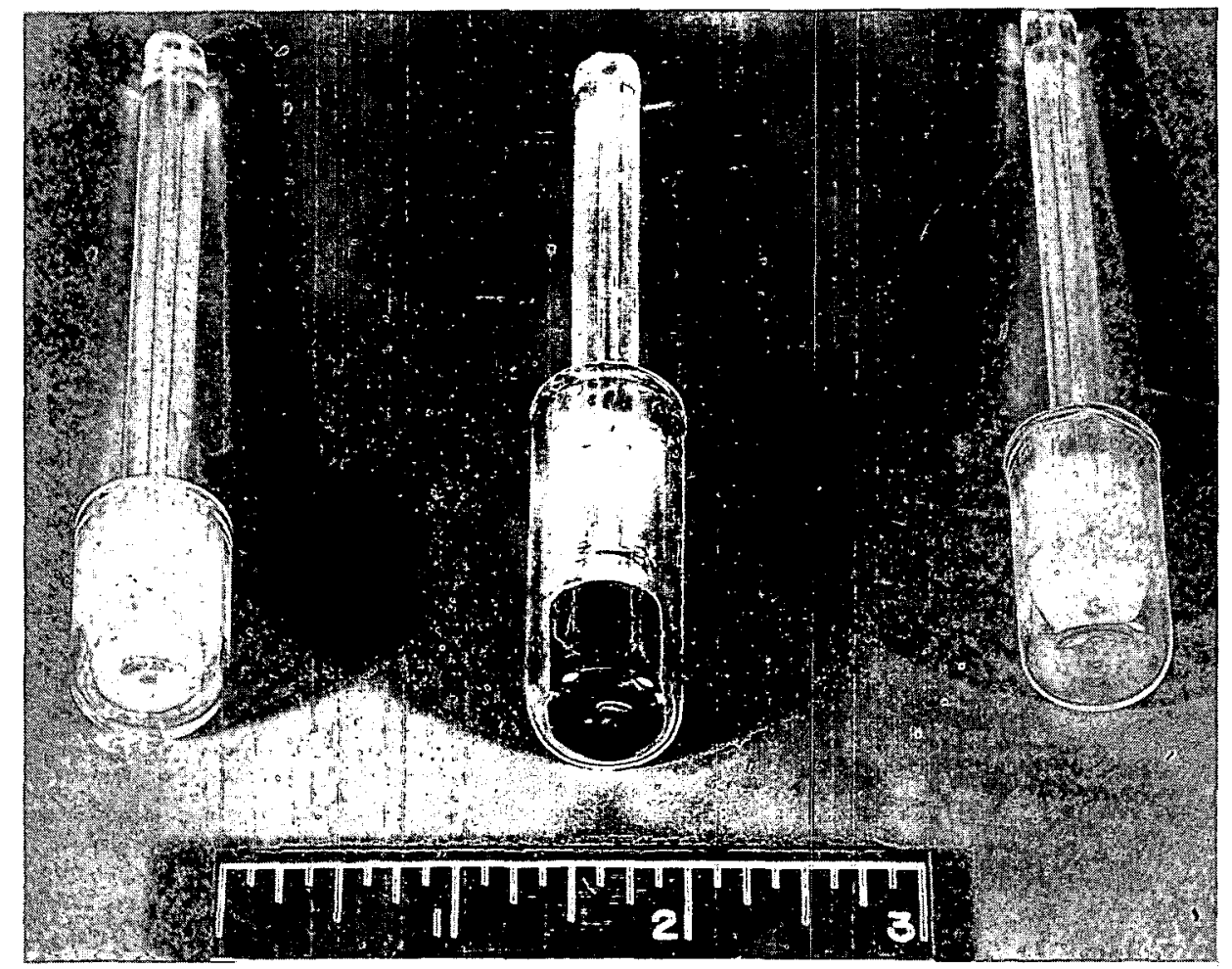

Figure 6. Quartz Sample Holders

pulled with a forepump, through Point 11 of Figure 1, the fine capillary was sealed, and Valve 5 opened again to further evacuate (to less than $10^{-5} \mathrm{~mm} \mathrm{Hg}$ ). Valves 5 and 6 were closed, a sample of krypton was let in, and Valve 4 was closed. The mercury was raised from bulb to bulb, and the value for $V_{\text {off }}$ recorded each time. The $V_{\text {off }}$ values can be translated to pressure, and the average number of moles of gas in the sample can be determined with the perfect gas law. Valve 5 was then opened, and the pressure at various bulb levels was measured again, which allowed an average value of the volume (VSC) from 
Point 14 of Figure 1 into the sample holder, to be determined. The system was evacuated again, Valve 5 was closed, another gas sample was let in, and the number of moles determined as before. Liquid nitrogen was placed around the sample to Point 17 (Figure 1), then Valve 5 was opened, and the pressure was measured at the different bulb levels again. The difference between the number of moles of original sample and the moles of gas left at each level allowed a calculation of the number of moles of gas adsorbed at each pressure. The temperature of the liquid nitrogen was measured with an oxygen vapor pressure thermometer, as shown in Figure 2. The temperature of the liquid nitrogen proved to be the same for all measurements $\left(77.2^{\circ} \mathrm{K}\right.$ or $-195.9^{\circ} \mathrm{C}$ ) and was determined from the oxygen vapor pressure data reported by Farkas and Melville. ${ }^{11}$ The vapor pressure of krypton at $77.2^{\circ} \mathrm{K}$ is calculated to be $2255.8 \mu$, from an equation relating vapor pressure and temperature, by Meihuizen and Crommelin. ${ }^{12}$ 


\section{CALCULATIONS*}

\section{$\underline{\text { STEP I }}$}

To determine an average value for VSC, (volume to the left of Point 14 of Figure 1), close Valve 5 to Point 14, close Valve 6, let in krypton, close Valve 4 to Point 16. Raise mercury to obtain the pressure at the $i^{\text {th }}$ level $\left(P_{i}\right)$ from 1 to $n$ levels. Open Valve 5 to Point 15 and again measure the pressure at the $i^{\text {th }}$ level $\left(P_{i}^{\prime}\right)$ from 1 to $n$ levels.

$$
V S C_{a v g}=\left[\sum_{i=1}^{n} V_{i}\left(\frac{P_{i}}{P_{i}^{\prime}}-1\right)\right] / n
$$

where $V_{i}$ 's are the known volumes, including $V_{d}$.

\section{STEP II}

Obtain a gas sample and determine the average number of moles $\left(N_{\text {avg }}\right)$. Evacuate, close Valve 5 to Point 14, close Valve 6, let in sample, close 4 to Point 16, record $P_{i}$ as before.

$$
N_{\text {avg }}=\left(\sum_{i=1}^{n} \frac{P_{i} V_{i}}{R T}\right) / n
$$

\section{STEP III}

To determine the moles of gas $\left(N_{i}\right)$ left in the system after adsorption has taken place at the pressures $P_{i}$, place liquid nitrogen around sample, to Point 17 , open Valve 5 to Point 15, record $P_{i}$ as before.

$$
N_{i}=P_{i} V_{i}^{\prime} / R T
$$

Now

$$
V_{i}^{\prime}=V_{i}+T V_{h} / 77.2+V_{s c}
$$

\footnotetext{
*Nomenclature used in this section is that set up to conform with the format used for the computer.
} 
where

$T=$ ambient (Item 2 of Figure 1) absolute temperature,

77.2 = temperature of the liquid nitrogen

$V_{h}=$ volume of the sample holder with the sample in.

The manner in which values for $V_{h}$ were obtained is given in Appendix I. $V_{s c}$ is the volume between Points 14 and 17 in Figure 1 , and is obtained by subtracting $V_{h}$ from $V S C$.

\section{STEP IV}

To obtain the number of atoms of krypton [(CAP)N] adsorbed on the sample and glass holder at pressure $P_{i}$,

$$
(C A P) N=\left(N_{\text {avg }}-N_{i}\right) 6.02 \times 10^{23}
$$

\section{STEP V}

A correction must be made to account for the difference in the pressure at the sample and that measured at the Thermistor, due to thermal transpiration. Since the volumetric buret and the sample holder are maintained at widely different temperatures, and are connected by a capillary tube with a diameter (2: $\mathrm{mm}$ ) close to the mean free path of the gas, thermal transpiration will, if neglected, lead to high values for $P_{i}$ around the sample. A correction for this has been worked out by Rosenberg ${ }^{7}$ in the form of an equation:

$$
P_{s c}=P_{B}\left[1-\frac{0.490}{37.2 D^{2}\left(P_{B}\right)^{2}+14.45 D P_{B}+1}\right] \text {, }
$$

where

$$
\begin{aligned}
P_{B} & =\text { pressure, in } \mathrm{mm} \mathrm{Hg}, \text { measured by the Thermistor, } \\
D & =\text { capillary diameter, in } \mathrm{mm} .
\end{aligned}
$$

This equation is subject only to the restriction that $P_{B} D>0.07 \mathrm{~mm} \mathrm{Hg}$. 


\section{STEP VI}

It is now possible to determine values for $P_{s c} / P_{o}$ and $P_{s c} /\left(P_{o}-P_{s c}\right) N$

(Note Equation 1), where $P_{o}$ is the vapor pressure of krypton at liquid nitrogen temperature and $N$ is $(C A P) N$, as determined above.

A plot is made of $P_{s c} /\left(P_{o}-P_{s c}\right) N$ vs $P_{s c} / P_{o}$ and a least squares slope and intercept of the line is evaluated.

The number of atoms in a monolayer is

$$
N_{m}=\frac{1}{\text { Slope }+I}
$$

where $l$ is the intercept. The sample surface area is just

$$
\text { Area }=N_{m} \times 19.41 \times 10^{-16} \mathrm{~cm}^{2}
$$

since it has been demonstrated ${ }^{7}$ that an atom of krypton covers $19.41 \times 10^{-16} \mathrm{~cm}^{2}$ on the surface. 


\section{IBM 709 COMPUTER PROGRAM}

Rather than plot values of $V_{\text {off }}$ vs pressure for the Thermistor calibrations, a fourth order polynomial expansion;

$$
P_{i}=A_{0}+A_{1} V_{o f f}+A_{2} V_{o f f}^{2}+A_{3} V_{o f f}^{3}+A_{4} V_{o f f}^{4}
$$

where the A's are constants, was found to correlate the data to the desired precision (to $0.1 \%$ ). To solve this equation for the five coefficients, at least five independent measurements were needed. Usually nine or more calibration measurements were made, which took about one hour each morning.

A complete program was written (on file at AI), in Fortran language, to solve Equation 12 for the coefficients by a least squares approximation, and then place all of the values of $V_{\text {off }}$ obtained during the experiment into this equation and solve for the $P_{i}$ 's. The computer would then, with the $P_{i}$ values and corresponding known volume values, compute all of the equations in Steps I through VI. It would then make a least squares approximation of $P_{s c} /\left(P_{o}-P_{s c}\right) N$ data, determine the slope of the line and the intercept, solve for the area of the sample, and report a root mean square error for each of these.

The computer would then plot the data $P_{s c} /\left(P_{o}-P_{s c}\right) N$ on a cathode-ray tube and photograph it. An example of the results returned from the computor for a surface area measurement is given in Appendix II (Figure 14). Photographs of the cathode-ray pictures are shown in Figure 15 of Appendix II. 


\section{RESULTS}

Figure 7 is an adsorption isotherm for krypton adsorbing on a $50-\mathrm{mg}$ sample of uranium dioxide at liquid nitrogen temperature $\left(77.2^{\circ} \mathrm{K}\right)$. It is seen that the curve is sigmoid, or a Type II isotherm, ${ }^{8}$ and showed no hysteresis on desorption. This type of isotherm is generally ascribed to multimolecular adsorption.

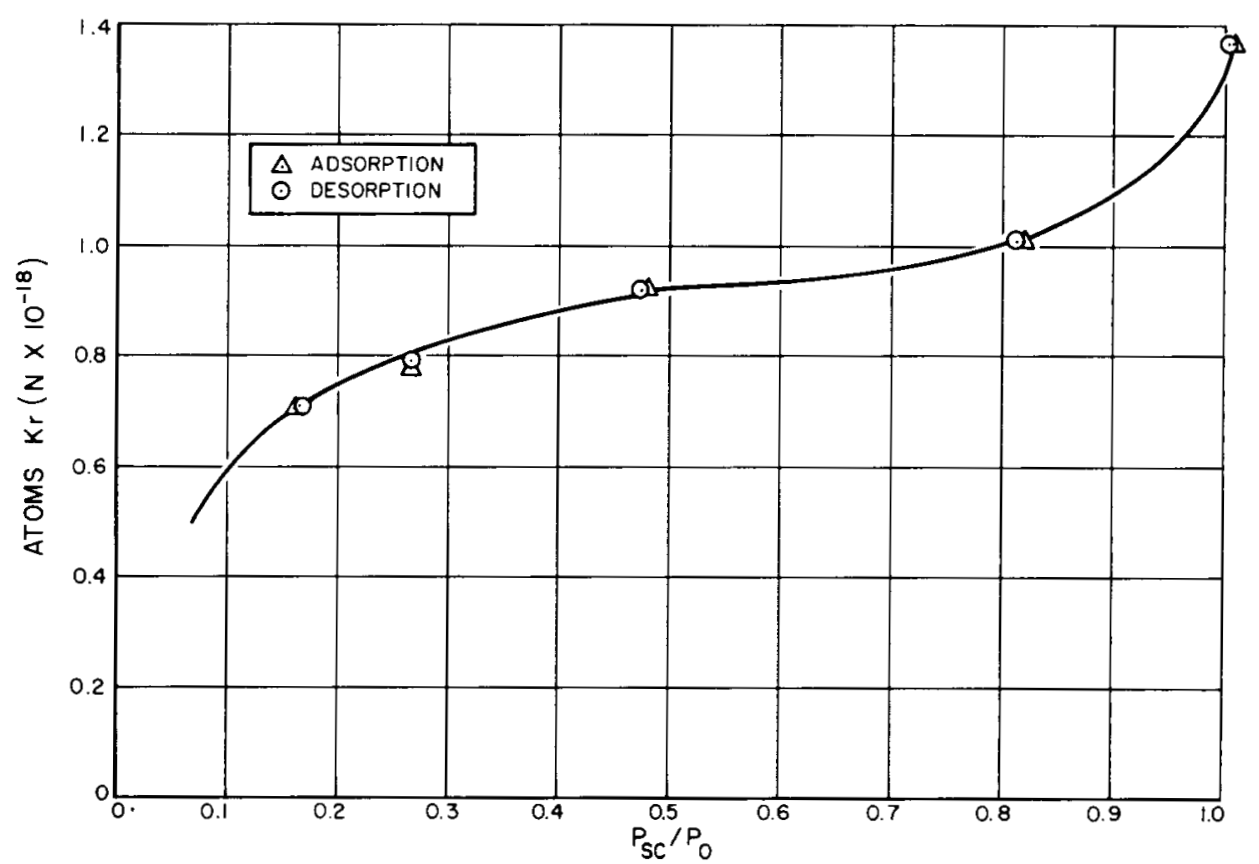

Figure 7. Krypton Adsorption Isotherm on 50-mg Sample (E) of $\mathrm{UO}_{2}$ Powder

The isotherm in Figure 8 is for a sintered $\mathrm{UO}_{2}$ pellet that contained $0.5 \%$ fissia (a mixture of fission product oxides). This pellet had a geometric density of $10.16 \mathrm{~g} / \mathrm{cc}$ and a wet density of $10.27 \mathrm{~g} / \mathrm{cc}$ (wet density measured by water displacement, $93.6 \% \mathrm{TD}$ ). The isotherm is similar to that for a $\mathrm{UO}_{2}$ powder, but shows a hysteresis effect on desorption, which is generally associated with capillary condensation. The pellet must have had many microscopic pores, with diameters of the order of atomic dimensions. This property is further illustrated in Figure 9, where the value of $V_{\text {off }}$ (pressure) is plotted as a function of time. 


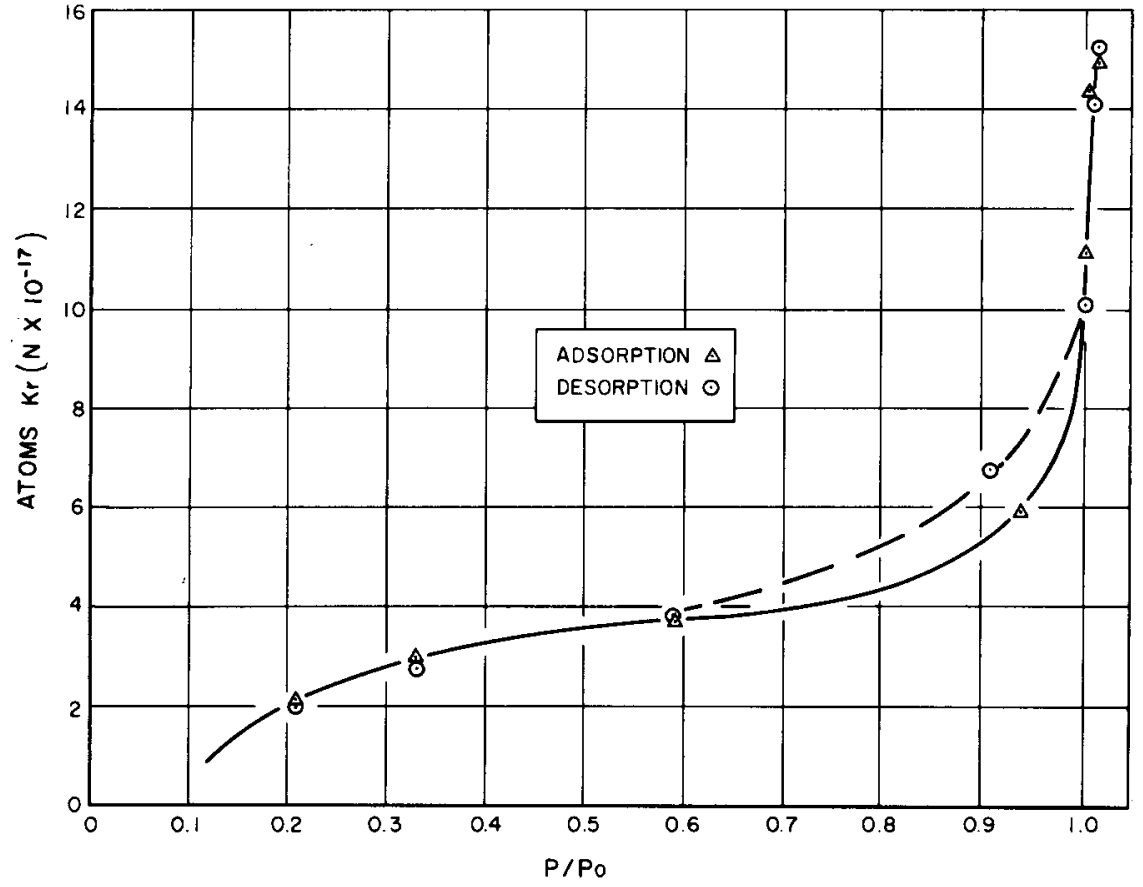

Figure 8. Krypton Adsorption Is otherm on Sintered $\mathrm{UO}_{2}$ Pellet (G-2-C-11, Wet Density 93.6\% TD), Showing Hysteresis on Desorption

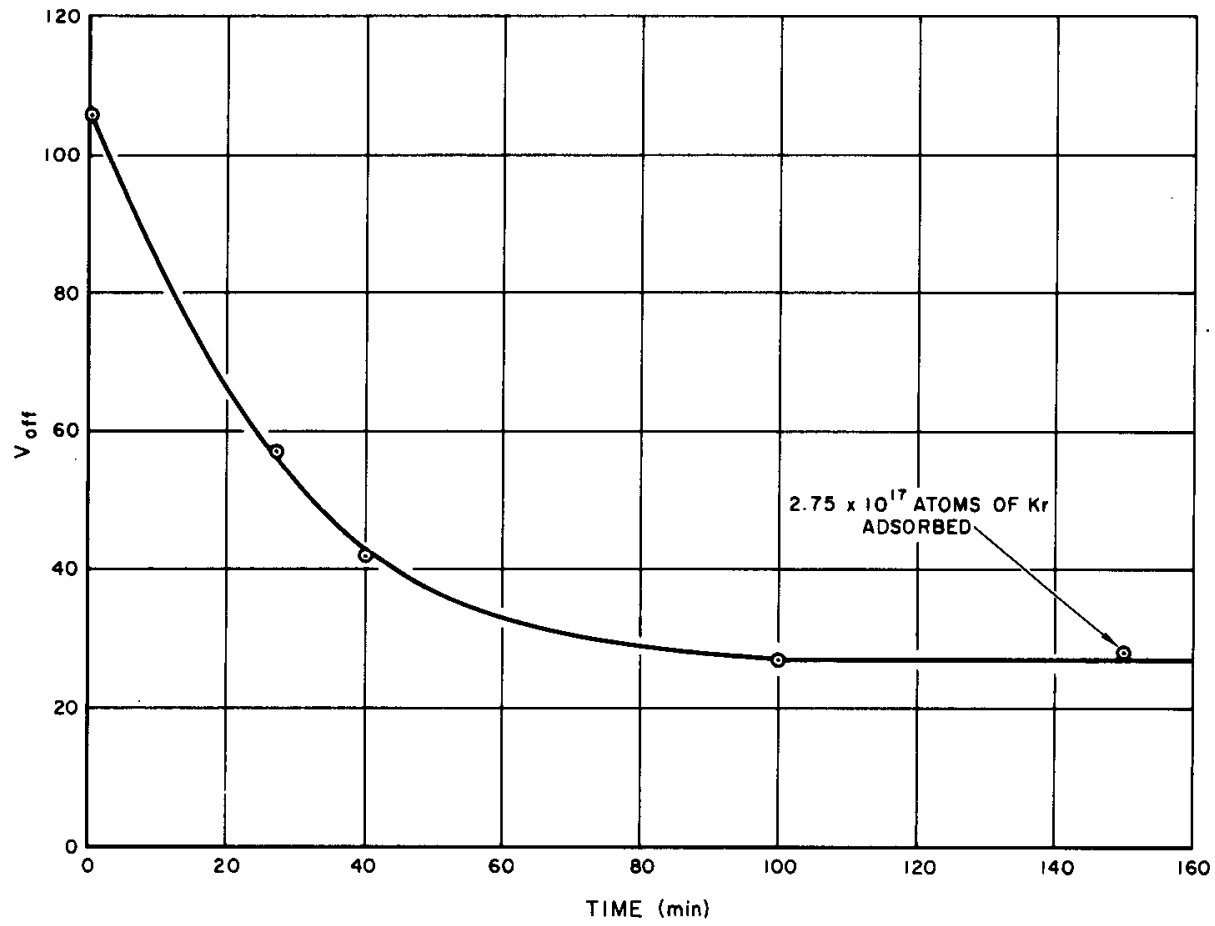

Figure 9. Time for Adsorption to Attain Equilibrium (Pellet G-2-C-11) 
Equilibrium was not reached for $100 \mathrm{~min}\left(2.75 \times 10^{17}\right.$ atoms of $\mathrm{Kr}$ adsorbed); whereas, for powder samples, it was almost instantaneous. The effect shown in Figure 9 is not due to a delay in the pellet coming to temperature equilibrium; because repeated experiments, in which the pellet was left in the liquid nitrogen for various lengths of time under vacuum (up to $2 \mathrm{hr}$ ), made no change on this curve. It is believed that equilibrium was not reached for about an hour, for most pellets, because of diffusion into the small capillaries.

\section{A. SURFACE AREA MEASUREMENTS}

Table III gives the results for a sintered uranium dioxide pellet (G-6-C-11), uranium dioxide powders, anatase powder, zirconia powder, and ceria powder. The first column in Table III identifies the sample; the second column gives the slope and the rms error of the BET plot $\left[P_{s c} /\left(P_{o}-P_{s c}\right) N \times 10^{18} v s P_{s c} / P_{o}\right]$; the third column gives the intercept and the rms error for the BET plots; column four gives the surface area and the rms error, and the fifth column gives the values for $\mathrm{C}$ in Equations 1 and 2. In Table III, the average values are given with the standard deviation for the different independent experiments. The root mean square error, recorded with each experiment, indicates the error involved for a single experiment; whereas the standard deviation, given with the average of a number of experiments on the same sample, indicates the reproducibility of the measurements. It is seen, for the sintered pellet, that the rms error for the slope of the BET plot averages about $1 \%$, the rms error for the intercept averages about $7 \%$, and the rms error for the surface area averages about $1.3 \%$. It is interesting to note that the surface areas are nearly a function of the slope of of the BET curve alone, since the intercept values are so small. For the sintered pellet, the surface area was reproducible to about $4 \%$. The average value of $C$ for the uranium dioxide pellet is $57.6 \pm 11.1$, as compared to $376 \pm 62$ for uranium dioxide powders. A larger value of the constant $C$ is indicative of a larger value for the heat of adsorption of the first layer. 
TABLE III

BET SURFACE AREA MEASUREMENTS OF VARIOUS MATERIALS

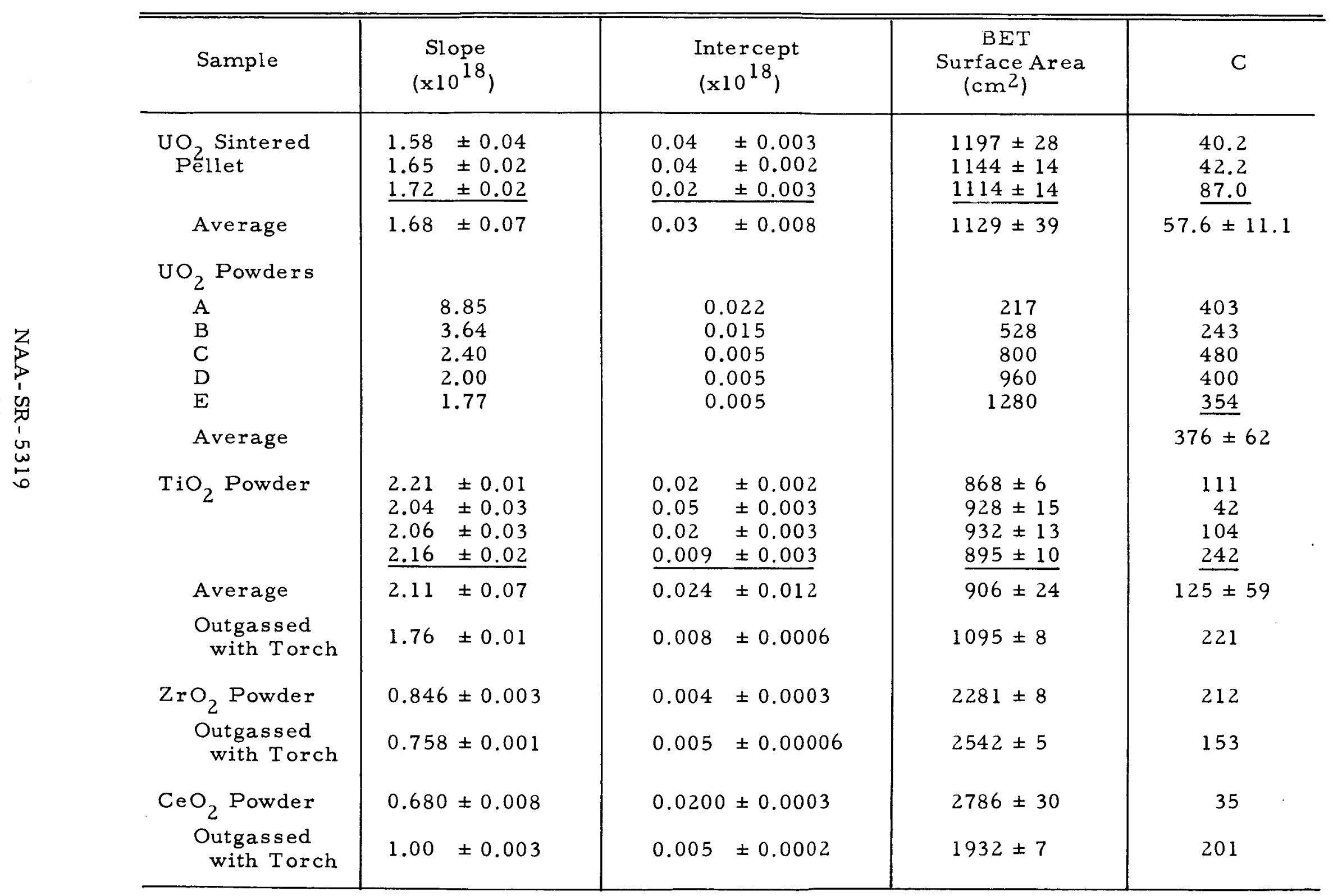

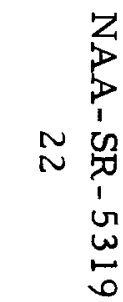


The average values of $C$ for anatase and ceria are $125 \pm 59$ and 35 respectively, when the samples were outgassed at room temperature. Outgassing samples at high temperature with a torch gave $C$ values for anatase, zirconia, and ceria of about 200 for all three samples. These values compare well with those of Rosenberg ${ }^{7}$ for krypton adsorbing on crushed germanium (i.e, freshly crushed germanium yielded a $C$ value of 204, as compared to 116 for the same germanium surface with a chemisorbed layer of oxygen). It is presumed that the effect of high temperature degassing of anatase and ceria, and probably zirconia, is to remove a chemisorbed gas, such as oxygen or water. Although outgassing at high temperatures increased the surface area of anatase from about 900 to $1100 \mathrm{~cm}^{2}$, it decreased the surface area of ceria from 2786 to $1932 \mathrm{~cm}^{2}$. One uranium dioxide pellet was outgassed at $600^{\circ} \mathrm{C}$ for $15 \mathrm{~min}$ for one experiment, and then outgassed at room temperature for the rest. The surface area proved to be $20 \%$ higher for the high temperature outgassing. All other experiments were outgassed at room temperature. It has been observed that greater precision is obtained if the measurements are made in the lowe $r$ pressure range [ e.g., many of the measurements were made in the $P_{s c} / P_{o}$ range of 0.05 to 0.3 (average rms error $\sim 1.3 \%$ ), whereas the anatase, zirconia, and ceria samples were measured in the $P_{s c} / P_{o}$ range of about 0.01 to 0.05 (average rms error $\sim 0.5 \%$ )].

As was mentioned in the introduction, a number of uranium dioxide powders had undergone various oxidation-reduction cycles $\left(\mathrm{UO}_{2}\right.$ to $\left.\mathrm{U}_{3} \mathrm{O}_{8}\right)$, and there was a need to correlate surface area with the number of oxidation-reduction cycles and the average particle diameter of the powder.

It was important to determine whether an accurate relationship could be found between the powder surface area and the average particle diameter, as measured with a Fisher Sub-Sieve Sizer (gas permeability method). If such a correlation could be made, the powder characteristics (as to diameter and specific surface area) could be determined very quickly $(\sim 5 \mathrm{~min} / \mathrm{sample})$ with the SubSieve Sizer, and the surface area measurements ( 2 to $3 \mathrm{hr} / \mathrm{sample}$ ) would not be necessary, in further powder metallurgical processing of uranium dioxide. Figure 10 gives BET plots for the five uranium dioxide powders. It is seen that, for $P_{s c} / P_{o}<0.25$, the experimental points fall on straight lines, as required by 


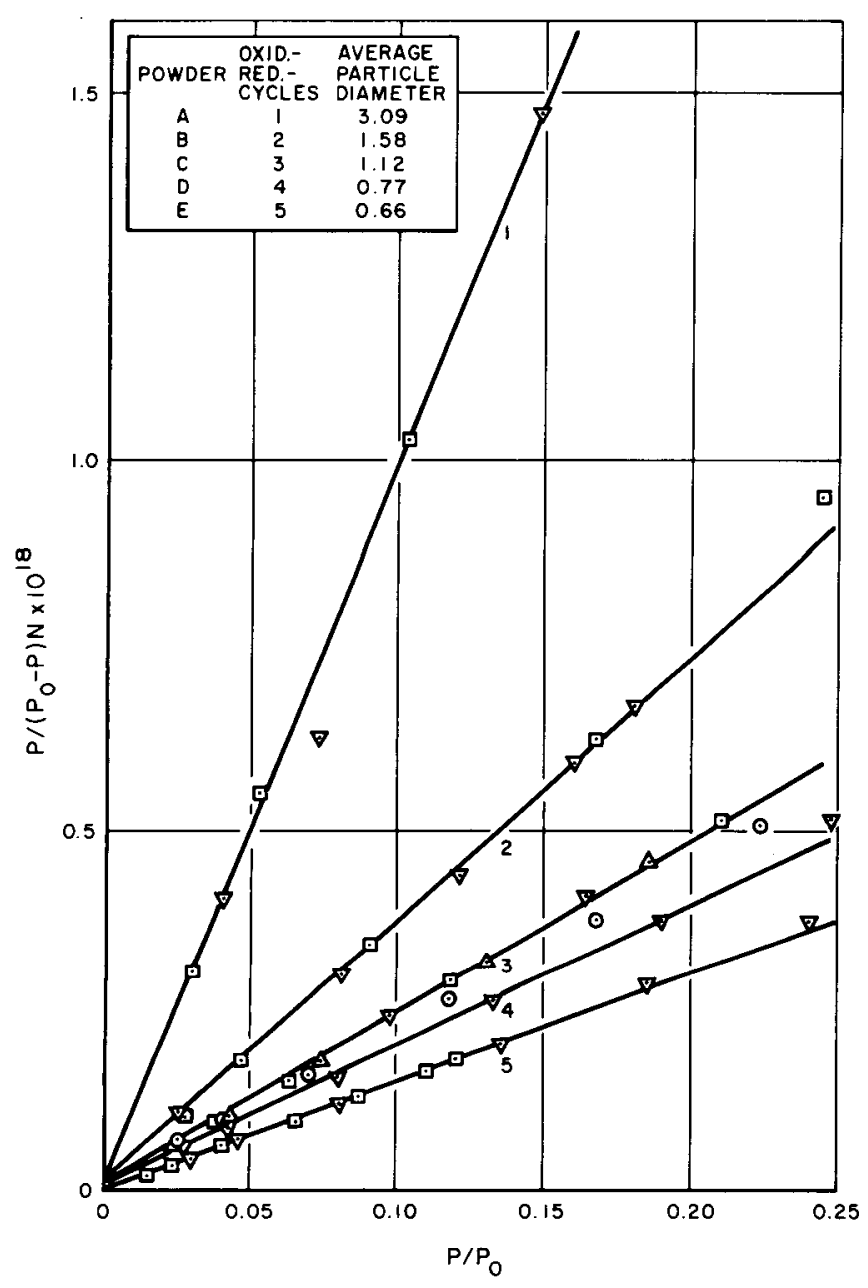

Figure 10. BET Plots of

$$
\frac{P \times 10^{-18}}{\left(P_{o}-P\right) N} \text { vs } \frac{P}{P_{o}}
$$

for $\mathrm{UO}_{2}$ Powders of

Various Average

Particle Sizes

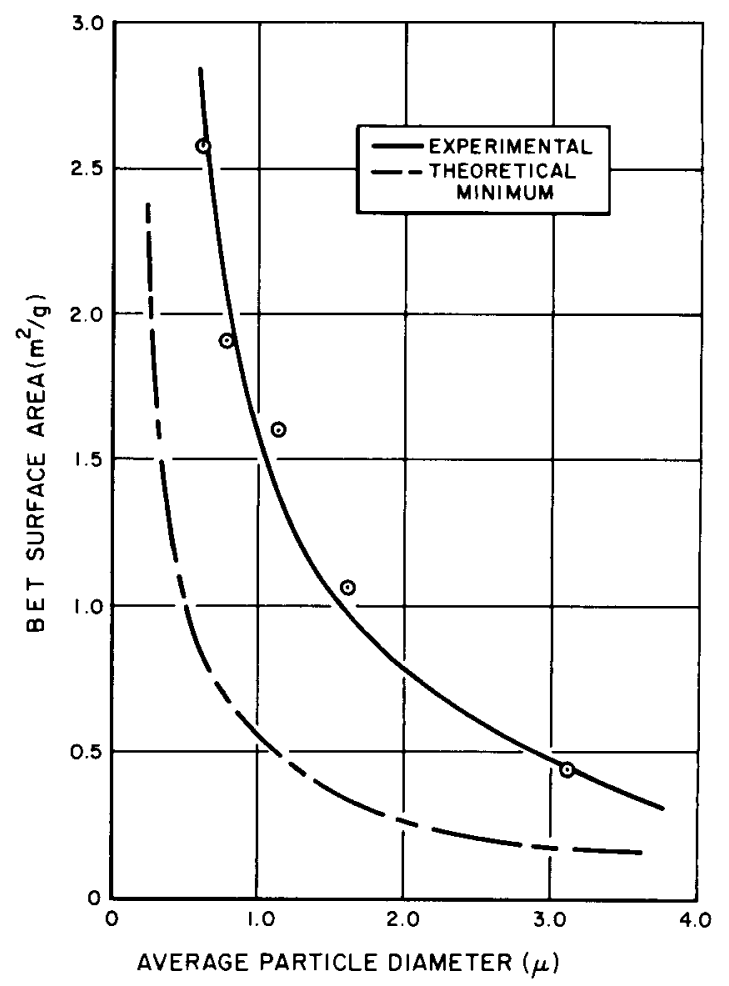

Figure 11. Correlation between

Surface Area and Average

Particle Diameter of

$\mathrm{UO}_{2}$ Powders 
theory. The lines converge at an intercept close to zero, and the slopes of the lines increase in a smooth manner with increasing particle size. Table IV gives the average surface area, as a function of particle size and the number of oxidation-reduction cycles. A graph relating specific surface area and average particle diameter is given in Figure 11 . It is seen that the experimental points fall close to the curve (a least squares fit of the experimental points).

TABLE IV

CORRELATION OF SURFACE AREA vs AVERAGE DIAMETER

\begin{tabular}{l|c|c|c|c|c}
\hline \hline Powder & $\begin{array}{c}\text { Number } \\
\text { Surface } \\
\text { Area } \\
\text { Measurements }\end{array}$ & $\begin{array}{c}\text { Sample } \\
\mathrm{Wt} \\
(\mathrm{mg})\end{array}$ & $\begin{array}{c}\text { Average } \\
\text { Surface } \\
\text { Area } \\
\left(\mathrm{cm}^{2}\right)\end{array}$ & $\begin{array}{c}\text { Specific } \\
\text { Surface } \\
\text { Area } \\
(\mathrm{m} 2 / \mathrm{g})\end{array}$ & $\begin{array}{c}\text { Average } \\
\text { Particle } \\
\text { Diameter } \\
(\mu)\end{array}$ \\
\hline $\mathrm{UO}_{2}$ & & & & & \\
$\mathrm{~A}$ & 2 & 48.6 & 217 & 0.446 & 3.09 \\
$\mathrm{~B}$ & 2 & 50.0 & 528 & 1.05 & 1.58 \\
$\mathrm{C}$ & 4 & 49.9 & 800 & 1.60 & 1.12 \\
$\mathrm{D}$ & 3 & 50.6 & 960 & 1.90 & 0.77 \\
$\mathrm{E}$ & 2 & 50.0 & 1280 & 2.56 & 0.66 \\
$\mathrm{TiO}_{2}$ & 1 & 10.1 & 1095 & 10.8 & 0.45 \\
$\mathrm{ZrO}_{2}$ & 1 & 50.4 & 2543 & 5.05 & 1.32 \\
$\mathrm{CeO}_{2}$ & 1 & 60.2 & 1932 & 3.21 & 0.96 \\
\hline
\end{tabular}

The lower curve in Figure 11 is a theoretical hyperbola, relating the surface area of spherical particles with particle diameter, the equation being

$$
S=6 / D \rho,
$$

where

$$
\begin{aligned}
& S=\text { specific surface area } \\
& \rho=\text { density of the material } \\
& D=\text { diameter of the spheres }
\end{aligned}
$$


For uranium dioxide, this equation becomes

$$
S=0.547 / D
$$

which is the equation for the lower curve in Figure 11. A log-log relationship for the experimental uranium dioxide data, averaged by the method of least squares, is:

$$
\log S=(-1.086 \pm 0.089) \log D+(0.2086 \pm 0.022)
$$

The data are plotted in Figure 12, the straight line being the least squares fit.

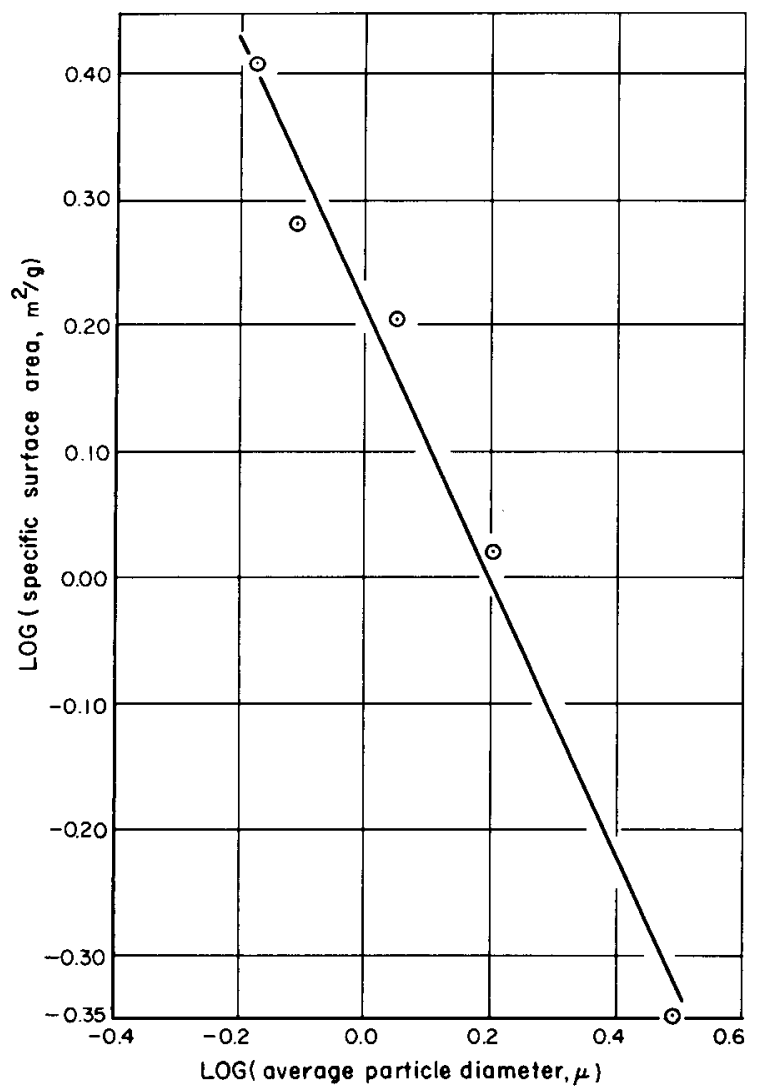

Figure 12. Log-Log Plot of Specific Surface Area vs Average Particle Diameter of $\mathrm{UO}_{2}$ Powders
From the experimental measurements on uranium dioxide, an equation relating surface area and average particle diameter is:

$$
S=1.68 / D
$$

Since the lower curve in Figure 11, or Equation 14, represent the minimum surface area for a particle of any diameter, a shape factor can be obtained as: $1.68 / 0.547=3.07$. The shape factor indicates how much the actual particles deviate from spheres. Microscopic examination of the powders show the particles to consist of aggregates of smaller particles. The Fisher Sub-Sieve Analyzer gives the average diameter of the aggregate, whereas the surface area is that of the individual particles (area that is exposed) in the aggregate. 
To determine whether the correlation for uranium dioxide was applicable in general (for other powders), powder samples of anatase, zirconia, and ceria were measured. The results are given in Table IV. The anatase sample was obtained from the National Bureau of Standards, with a statement saying that the powder had a surface area of $10.4 \mathrm{~m}^{2} / \mathrm{g} \pm 5 \%$, as measured by the BET method in a number of different laboratories. Measurement of a $10.1 \mathrm{mg}$ sample of this anatase (after outgassing with a torch, a standard procedure) gave $10.8 \mathrm{~m}^{2} / \mathrm{g} \pm 3 \%$ (Note Table IV). The average particle diameter of the anatase proved to be $0.45 \mu$, which gave a surface area of $10.8 \mathrm{~m}^{2} / \mathrm{g}$, using the uranium dioxide correlation (Equation 15). This result is surprising, in view of the extreme extrapolation. However, the zirconia $(D=1.32 \mu$ ) had a surface area of $5.05 \mathrm{~m}^{2} / \mathrm{g}$, as compared to $2.38 \mathrm{~m}^{2} / \mathrm{g}$ from the correlation; and ceria had a surface area of $3.21 \mathrm{~m}^{2} / \mathrm{g}$, as compared to $2.57 \mathrm{~m}^{2} / \mathrm{g}$ from the correlation.

\section{B. SURFACE AREA OF DUMMY QUARTZ SAMPLE HOLDERS}

In order to determine the surface area of uranium dioxide pellets, it is necessary to know the surface area of the glass holder, since the surface areas of both the holder and the pellet are measured. For powder samples, the glass surface area was negligibly small; whereas, for pellets, the surface of the glass is of the same magnitude as the pellet. Since the pellets were sealed into the glass holders (Note Figure 6) and were sealed to the system, there was no way of measuring the holder area independently. To eliminate the surface area of the pellet sample holders, three quartz dummy holders (with no pellets) were made with different volumes (two of these are seen in Figure 6).

Results of the surface area measurement of these holders are given in Table $\mathrm{V}$. The first column in Table $\mathrm{V}$ gives the volume of the holder, the second column gives the slope and rms error for the BET curve, column three gives the intercept and rms error for the BET plots, column four gives the surface area and rms error, column five gives the geometric area of the holders, column six gives the roughness factors (BET area divided by the geometric area), and column seven gives the values for the constant $C$.

If it is assumed that the quartz in each holder had the same roughness factor, it is seen, from Table V, that some other factor is influencing the measurements, since the calculated roughness factors decrease with increasing volume. A check 
TABLE V

DETERMINATION OF SURFACE AREAS OF DUMMY QUARTZ SAMPLE HOLDERS

\begin{tabular}{|c|c|c|c|c|c|c|}
\hline $\begin{array}{l}\text { Holder } \\
\text { Volume } \\
\left(\mathrm{cm}^{3}\right)\end{array}$ & $\begin{array}{l}\text { Slope } \\
(x 1017)\end{array}$ & 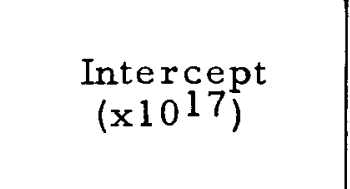 & $\begin{array}{l}\text { BET } \\
\text { Surface } \\
\text { Area } \\
\left(\mathrm{cm}^{2}\right)\end{array}$ & $\begin{array}{c}\text { Geometric } \\
\text { Area } \\
\left(\mathrm{cm}^{2}\right)\end{array}$ & $\begin{array}{l}\text { Roughness } \\
\text { Factor }\end{array}$ & $\mathrm{C}$ \\
\hline \multirow[t]{4}{*}{1.60} & $1.10 \pm 0.02$ & $0.02 \pm 0.003$ & $172 \pm 3$ & 23.1 & 7.5 & 51 \\
\hline & $0.97 \pm 0.04$ & $0.08 \pm 0.007$ & $183 \pm 8$ & & 7.9 & 13 \\
\hline & $1.11 \pm 0.06$ & $-0.04 \pm 0.016$ & $180 \pm 10$ & & 7.8 & 29 \\
\hline & & \multicolumn{2}{|c|}{ Average $178 \pm 4$} & & 7.7 & 31 \\
\hline \multirow[t]{7}{*}{2.17} & $1.71 \pm 0.12$ & $0.005 \pm 0.019$ & $113 \pm 8$ & 25.0 & 4.5 & 34 \\
\hline & $2.90 \pm 0.14$ & $0.08 \pm 0.029$ & $65 \pm 3$ & & 2.6 & 37 \\
\hline & $2.51 \pm 0.20$ & $0.09 \pm 0.045$ & $75 \pm 6$ & & 3.0 & 29 \\
\hline & $4.21 \pm 0.36$ & $0.01 \pm 0.088$ & $46 \pm 4$ & & 1.8 & 42 \\
\hline & $2.42 \pm 0.14$ & $0.05 \pm 0.039$ & $78 \pm 5$ & & 3.1 & 49 \\
\hline & $2.26 \pm 0.21$ & $0.09 \pm 0.058$ & $82 \pm 8$ & & 3.3 & 26 \\
\hline & & Averag & $77 \pm 15$ & & 3.0 & 36 \\
\hline 2.97 & $3.80 \pm 0.38$ & $0.21 \pm 0.005$ & $48 \pm 5$ & 28.3 & 1.6 & 19 \\
\hline
\end{tabular}


of the possibility that the problem might be in the correction for gas volume at liquid nitrogen temperature is as follows. In Table VIII of Appendix II, it is seen that an error of about $0.2 \mathrm{~cm}^{3}$ in the measurement of the holder volume changes the surface area determination by about $40 \mathrm{~cm}^{2}$ [i.e., the $2.17 \mathrm{~cm}^{3}$ holder would have to be low by $0.6 \mathrm{~cm}^{3}\left(1.57 \mathrm{~cm}^{3}\right)$ to yield a roughness factor of 7.7]. Since the holder volumes were measured to $\pm 0.06 \mathrm{~cm}^{3}$, the problem does not lie here.

There is a possibility that the different glass holders did have different roughness factors, and that Table $\mathrm{V}$ is entirely correct. It can be seen, in Figure 6 , that the holder on the left (Volume $=1.60 \mathrm{~cm}^{3}$, Table V) had more heat treatment during glass blowing than the one on the right $\left(\right.$ Volume $=2.17 \mathrm{~cm}^{3}$, Table V) by the whitening effect on the outside surface. The larger holdex (Volume $=2.97 \mathrm{~cm}^{3}$ ), although not shown in Figure 6, looked much like the central sample holder in Figure 6.

Most of the holders containing pellets had gas volumes of about $2.7 \mathrm{~cm}^{3}$; so that, as a good estimate, a value of 2 was used for the roughness factor of the quartz.

Rosenberg ${ }^{7}$ reports a roughness factor of 1.8 for Pyrex glass. His value of $\mathrm{C}$ for quartz was 48 , as compared with an average of 31 or 36 in Table $\mathrm{V}$.

A good estimate of a pellet surface area was made by subtracting the surface area of the glass holder, using a roughness factor of 2 (or about $70 \mathrm{~cm}^{2}$, in most cases).

\section{SURFACE AREA OF UO PELLETS, USED TO CORRELATE}

In the introduction, it was mentioned that a prime purpose for the surface area device was to measure the true surface area of uranium dioxide pellets, so that the rates of oxidation could be correlated. It is of vital importance to know the surface area available for reaction with a gas, for heterogeneous, gas-solid, reactions, if a theoretical interpretation is to be made.

Table VI gives the surface area and roughness factors for uranium dioxide pellets that had been surface oxidized at $362^{\circ} \mathrm{C}$ and $590 \mathrm{~mm} \mathrm{Hg}$ oxygen pressure. 
The first column in Table VI identifies the pellet, the second column gives the number of oxidation-reduction cycles the pellet had undergone (oxidation was allowed to not more than $0.5 \mathrm{mg}$ of oxygen pickup on the pellet surface and was then reduced with hydrogen), the third column gives the average ( 3 or 4 measurements) surface area of the pellet, with the standard deviation, and column four gives the roughness factor for each pellet (the pellets weighed approximately $16.5 \mathrm{~g}$, and had a geometric surface area of $7.7 \mathrm{~cm}^{2}$ ). These surface areas were used to correlate the rates of oxidation for the various pellets which are reported in another technical report. ${ }^{13}$

\section{TABLE VI}

SURFACE AREA OF $\mathrm{UO}_{2}$ PELLETS

\begin{tabular}{l|c|c|c}
\hline Pellet* & $\begin{array}{c}\text { Number of } \\
\text { Oxidation- } \\
\text { Reduction } \\
\text { Cycles }\end{array}$ & $\begin{array}{c}\text { BET Pellet } \\
\text { Surface } \\
\text { Area } \\
\left(\mathrm{cm}^{2}\right)\end{array}$ & $\begin{array}{c}\text { Roughness } \\
\text { Factor } \\
(f)\end{array}$ \\
\hline G-4-C-7 & 1 & $69 \pm 17$ & 9 \\
G-3-C-12 & 6 & $150 \pm 8$ & 19 \\
G-2-C-11 & 14 & $388 \pm 30$ & 50 \\
G-1-C-12 & 26 & $480 \pm 40$ & 62 \\
G-1-C-11 & 19 & $753-$ & 98 \\
G-6-C-14 & 0 & $1061 \pm 40$ & 105 \\
G-6-C-11 & 20 & 26 & 138 \\
G-5-C-12 & 26 & 249 \\
\hline
\end{tabular}

* The pellets had a geometric area of $7.7 \mathrm{~cm}^{2}$ and were oxidized with pure oxygen at $590 \mathrm{~mm} \mathrm{Hg}$ and $362^{\circ} \mathrm{C}$. 


\section{SUMMARY AND CONCLUSIONS}

A gas adsorption apparatus has been built to measure the surface area of sintered pellets and powder samples. The apparatus was of the conventional burette mercury type, but a Thermistor was used for precise pressure measurement ( 0 to $2000 \mu)$.

Sintered uranium dioxide pellets, with surface areas between 50 and $2000 \mathrm{~cm}^{2}$, have been measured with a precision of $1.3 \%$ and a reproducibility of about $4 \%$. The surface area of powder samples of uranium dioxide, anatase, zirconia, and ceria, as small as 10 to $50 \mathrm{mg}$, have been measured with a precision as high as $0.5 \%$ and a reproducibility of about $3 \%$.

A correlation was made between the surface area and average particle diameter of a set of uranium dioxide powders that had undergone various oxidation-reduction cycles. It was concluded that an excellent correlation exists, and that a powder surface area can be accurately predicted by rapid measurement of the average particle diameter ( $\sim 5$ min per sample) with a Fisher Sub-Sieve Sizer.

Measurement of the surface area of sintered uranium dioxide pellets allowed a comparison of oxidation rates, as a function of true surface area.

The goal of high precision has been accomplished. From 2 to $3 \mathrm{hr}$ are required to make the $B E T$ measurements, and all of the computations are made by the IBM computer in less than $1 \mathrm{~min}$. 


\section{APPENDIX I \\ METHOD FOR DETERMINATION OF VOLUME AVAILABLE TO GAS IN SAMPLE HOLDERS}

It is seen, from Figure 6, that an accurate determination of the volume in a sample holder cannot be made from the holder geometry.

Figure 13 is a drawing of an apparatus used to measure the surface area of powder samples by the Innes Method. ${ }^{14}$ An apparatus similar to this was used, with the exceptions that the constant temperature bath was not necessary, and the samples (as shown in Figure 6) were attached with Tygon tubing, rather than a ground glass joint.

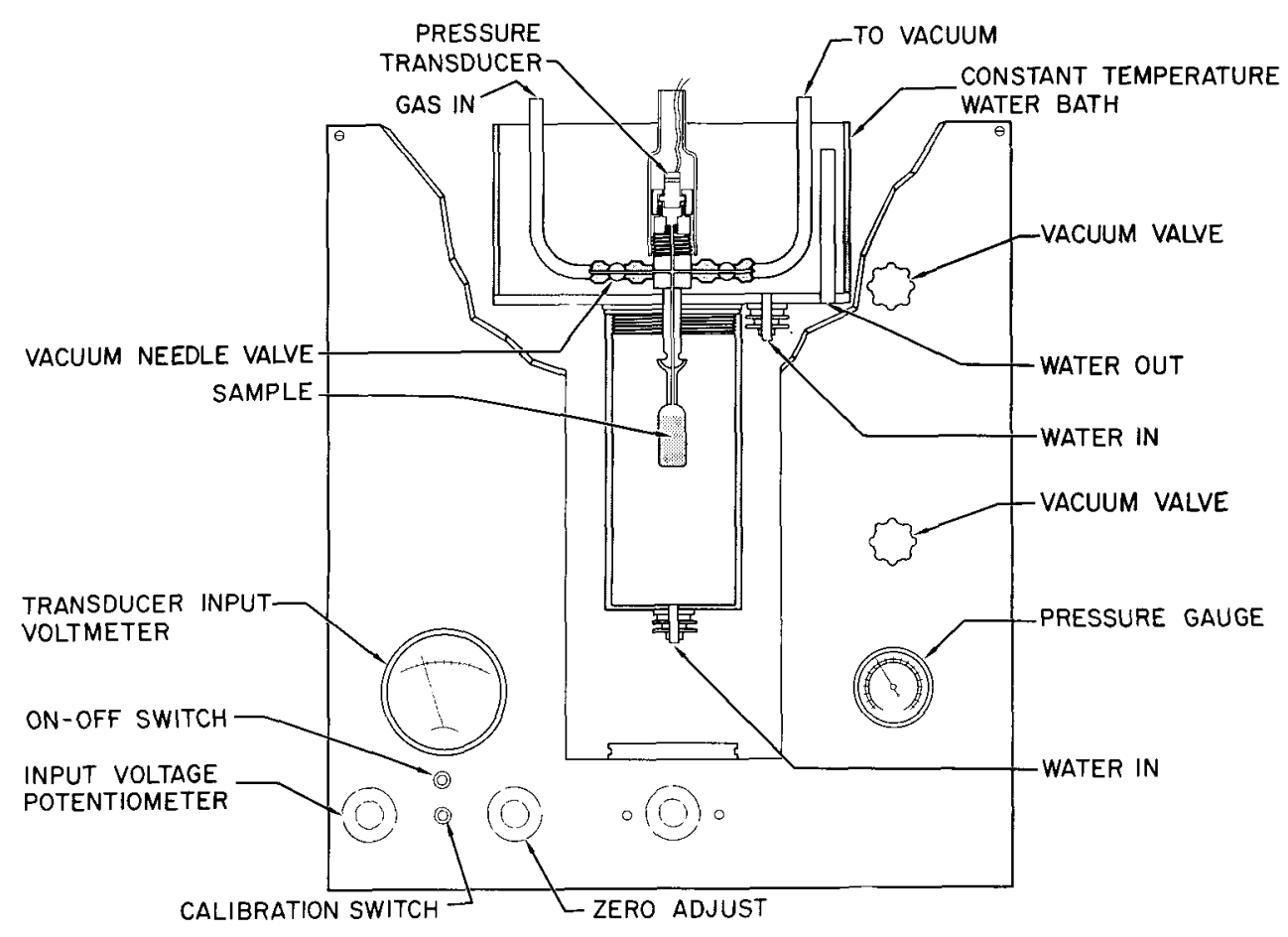

Figure 13. Surface Area Measuring Device

The pressure in the system could be recorded, as a function of time, with a pressure transducer (Statham PA 130-25-350) connected to a Leeds Northrup variable span recorder. The transducer pressure range was 0 to 25 psia, and its calibration factor was $188.6 \mu \mathrm{v}$ (open circuit) per volt per psi. It was necessary to have a constant input pressure. To accomplish this, a low pressure regulator was attached to a nitrogen tank. On the lower pressure side of the regulator, a precision pressure gauge was connected (Ashcroft Laboratory test gauge: 4-1/2-in. dial, 0 to $30 \mathrm{psi}$, Cat. No. 1082A), and then connected to the inlet tube (Figure 13). A forepumpwas connected to the vacuum outlet (Figure 13). 
The procedure for measuring the volume in a sample holder was as follows: a sample holder, similar to those in Figure 6, was attached with Tygon tubing and evacuated $(<10 \mu)$. The valve to the vacuum pump was closed, and the system was tested for leaks by watching the recorder; if the recorder remained at zero, there were no leaks.

Next, the gas inlet needle valve was cracked just enough to let the pressure rise at a suitable rate. It was found that, if a constant fore-pressure was maintained, the pressure would rise between 0 and $100 \mathrm{~mm} \mathrm{Hg}$ with a constant reproducible rate. Once the intake needle valve was adjusted to give the proper rate of pressure increase, it was not touched until the measurement was complete.

The intake needle valve allowed the gas to enter at such a slow rate that the system could be evacuated without closing this valve. The rate of gas inlet was measured, first with the sample holder, then with a known volume glass holder, and then with a cap. This was repeated two or three times, to give an average value. An example of the determination of a sample holder volume is as follows:

Let $V_{c a l}$ be the volume of a glass tube calibrated by weighing it with and without water.

Let $V_{h}$ be the volume of the sample holder.

Let $V_{c}$ be the volume in the system between the needle valves and down to where the sample holder is attached.

The calibrated volume was $3.675 \pm 0.003 \mathrm{~cm}^{3}$. The rate that the nitrogen entered the system was assumed to be constant, with a constant fore-pressure and a constant needle valve setting. Then, from the perfect gas law,

$$
R T \frac{d n}{d t}=V_{c} \frac{d P_{c}}{d t}=\left(V_{c}+V_{c a l}\right) \frac{d P_{c a l}}{d t}
$$

where

$$
\begin{aligned}
R & =\text { gas constant } \\
T & =\text { absolute temperature, } \\
d n / d t & =\text { rate gas passes the intake needle valve, } \\
t & =\text { time. }
\end{aligned}
$$


Now, $P$ is directly proportional to the voltage, as read from the recorder chart paper, so let

$$
\frac{d m v}{d t}=\frac{K d P}{d t}=R
$$

where

$$
\begin{aligned}
m v & =\text { millivolt reading from the chart paper } \\
K & =\text { proportionality constant }
\end{aligned}
$$

so that $R$ is the slope of the line on the chart paper. It can be seen that Equation 17 can be written

$$
V_{c} R_{c}=\left(V_{c}+V_{c a l}\right) R_{c a l}
$$

or

$$
V_{c}=\left(\frac{R_{c a l}}{R_{c}-R_{c a l}}\right) V_{c a l}
$$

where $R_{c}$ and $R_{c a l}$ are the slopes of the lines on the chart paper during the time the cap was on and the calibrated volume was on, respectively.

Now

$$
V_{c} R_{c}=\left(V_{c}+V_{h}\right) R_{h}
$$

so

$$
V_{h}=\left(\frac{R_{c}-R_{h}}{R_{h}}\right) V_{c}
$$

For the holder containing a $\mathrm{UO}_{2}$ pellet (G-5-C-12), 


$\begin{array}{ccc}\begin{array}{c}\text { Mst } \\ \text { Measurement }\end{array} & \begin{array}{c}2 \mathrm{nd} \\ R_{c}=0.909\end{array} & \begin{array}{c}\text { Measurement } \\ \text { Measurement }\end{array} \\ R_{c a l}=0.222 & 0.909 & 0.926 \\ R_{h}=0.272 & 0.266 & 0.222\end{array}$

Then

$$
V_{c}=\frac{0.222}{0.909-0.222} \times 3.675=1.187 \mathrm{~cm}^{3}
$$

and

$$
V_{h}=\frac{(0.909-0.272)}{0.272} \times 1.187=2.787 \mathrm{~cm}^{3}
$$

An average value for the three measurements is $V_{h}=2.847 \pm 0.040 \mathrm{~cm}^{3}$.

Table VII gives the results for a number of sample holders with pellets and also the three dummy glass holders.

TABLE VII

\begin{tabular}{|c|c|c|c|c|c|c|}
\hline \multirow{2}{*}{$\begin{array}{l}\text { Holder } \\
\text { with } \\
\text { Pellet }\end{array}$} & \multicolumn{5}{|c|}{$V_{h}$} & \multirow{2}{*}{ Average } \\
\hline & lst & $2 \mathrm{nd}$ & $3 \mathrm{rd}$ & 4 th & 5 th & \\
\hline$G-5-C-12$ & 2.787 & 2.877 & 2.877 & 2.877 & - & $2.847 \pm 0.040$ \\
\hline$G-6-C-11$ & 2.333 & 2.311 & 2.299 & - & - & $2.314 \pm 0.012$ \\
\hline$G-2-C-11$ & 3.770 & 3.770 & 3.771 & - & - & $3.770 \pm 0.0003$ \\
\hline$G-1-C-12$ & 2.693 & 2.661 & 2.727 & 3.101 & - & $2.796 \pm 0.153$ \\
\hline$G-6-C-14$ & 2.916 & 2.935 & 3.101 & 2.727 & 2.757 & $2.887 \pm 0.116$ \\
\hline$G-6-C-13$ & 5.234 & - & - & - & - & 5.234 \\
\hline G- $4-C-7$ & 1.783 & - & - & - & - & 1.783 \\
\hline $\begin{array}{l}\text { Small Dummy } \\
\text { Quartz Holder }\end{array}$ & 1.665 & 1.565 & - & - & - & $1.615 \pm 0.050$ \\
\hline $\begin{array}{l}\text { Dummy Quartz } \\
\text { Holder }\end{array}$ & 2.17 & - & - & - & - & 2.17 \\
\hline $\begin{array}{l}\text { Dummy Quartz } \\
\text { Holder }\end{array}$ & 2.97 & 2.83 & 2.73 & - & - & $2.84 \pm 0.08$ \\
\hline
\end{tabular}

VOLUMES OF QUARTZ SAMPLE HOLDERS 


\section{APPENDIX II \\ EFFECT OF EXPERIMENTAL ERRORS ON SURFACE AREA DETERMINATION}

To determine the effect of experimental errors on the final surface area determination, experimental data from a given experiment were sent to the computer a number of times with only one variable change each time. Table VIII gives the results of these computations.

From Table VIII and other data, it is seen that the effect of experimental error increases rapidly as the surface area decreases below about $100 \mathrm{~cm}^{2}$. It should be pointed out that the holder volume $\left(V_{h}\right)$ is corrected for liquid nitrogen temperature by multiplying by $300 / 77.2 \approx 4$, which magnifies an error in $V_{n}$ by a factor of 4 . Then a $7 \%$ error in $V_{n}$ is equivalent to a $28 \%$ error in $V_{c}$ or VSC. Even so, the error in the calculated surface area of $80 \%$ is much higher, for the low surface area glass holder, as compared to the equivalent error for the $135 \mathrm{~cm}^{2}$ surface $(7 \times 2)$ of $14 \%$.

A change in the vapor pressure of krypton of $0.7 \%$ changed the calculation of the surface area by only $0.1 \%$.

Switching Thermistor calibration data changed the calculated surface area by $2 \%$, in two cases, and by 16 and $21 \%$, in two other cases. The worst problem encountered in this study was the instability of the Thermistor. It may be that a Thermistor with a dissipation constant of 0.1 , with a lower power requirement, may give better stability, as found by Rosenberg. ${ }^{7}$ 
TABLE VIII

EFFECT OF ERRORS ON CALCULATED SURFACE AREA

\begin{tabular}{|c|c|c|c|c|c|c|}
\hline & \multicolumn{3}{|c|}{ Change in Measured Variable } & \multicolumn{3}{|c|}{$\begin{array}{c}\text { Change in Surface Area } \\
\text { Calculation } \\
\left(\mathrm{cm}^{2}\right)\end{array}$} \\
\hline & From & To & $\begin{array}{l}\text { Error } \\
(\%)\end{array}$ & From & To & $\begin{array}{l}\text { Error } \\
(\%)\end{array}$ \\
\hline$V_{d}\left(\mathrm{~cm}^{3}\right)$ & 6.340 & 6.040 & 5 & 135 & 132 & 2 \\
\hline$V_{h}\left(\mathrm{~cm}^{3}\right)$ & 2.97 & 2.77 & 7 & 48.4 & 86.5 & 80 \\
\hline$P_{o}(\mu)$ & 2255.8 & 2270 & 0.7 & 1893 & 1895 & 0.1 \\
\hline \multicolumn{4}{|c|}{$\begin{array}{l}\text { Switched calibration data with those of another } \\
\text { day }\end{array}$} & 556 & 568 & 2 \\
\hline \multicolumn{4}{|c|}{$\begin{array}{l}\text { Switched calibration data with those of another } \\
\text { day }\end{array}$} & 473 & 461 & 2 \\
\hline \multicolumn{4}{|c|}{$\begin{array}{l}\text { Switched calibration data with those of another } \\
\text { day }\end{array}$} & 969 & 835 & 16 \\
\hline \multicolumn{4}{|c|}{$\begin{array}{l}\text { Switched calibration data with those of another } \\
\text { day }\end{array}$} & 1053 & 871 & 21 \\
\hline
\end{tabular}


LEAST SUUARES AFFRGNIMATIOH EY FOLYYOMIAL OF BROER 4 TO 9 POINTS

EY THE METHOO OF FFACTIOHAL RESILUALS

MORTAL EQUATIONS

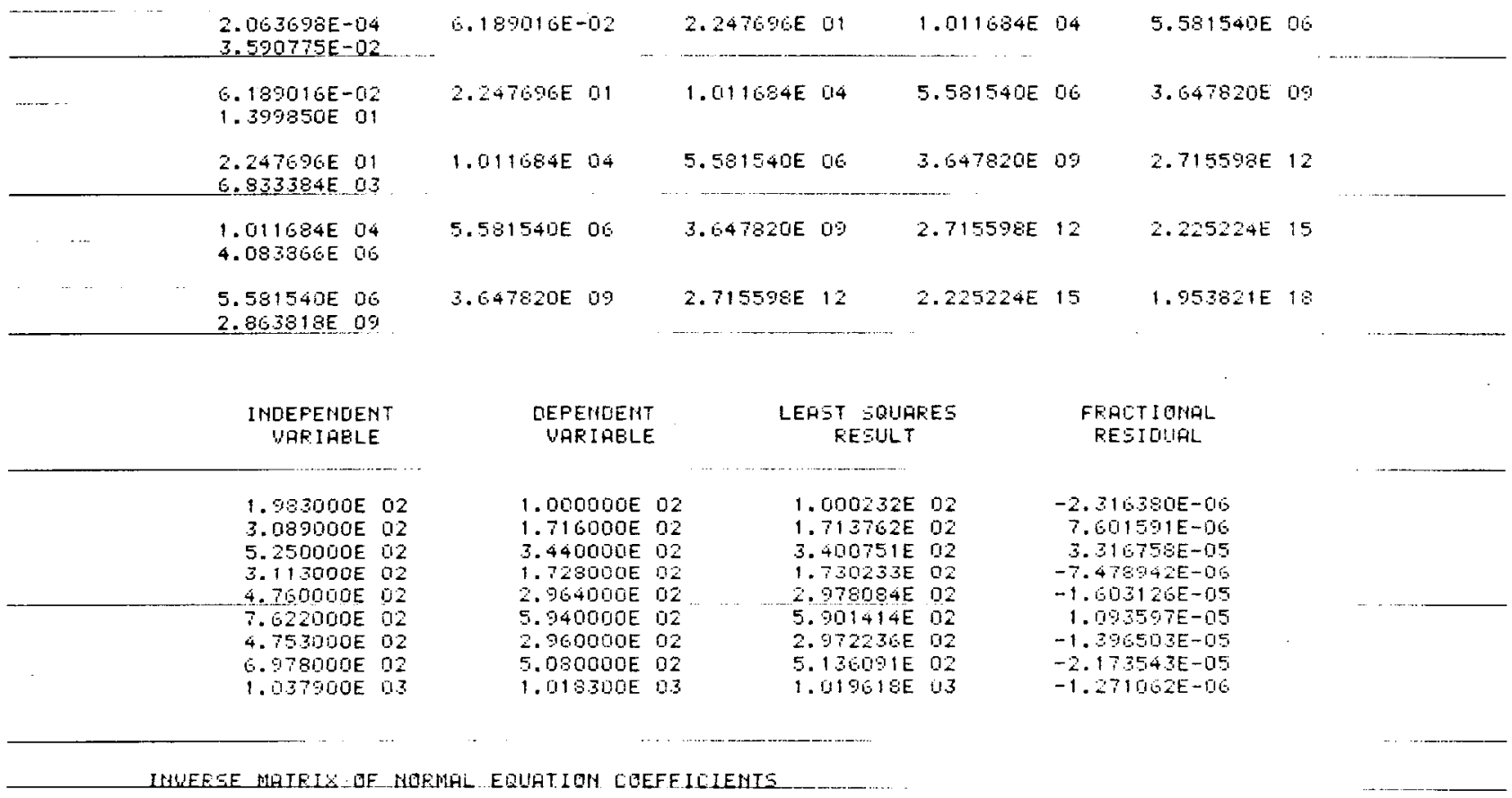

IHUESE MAIELX. OF_NOEMHL EQUATION COEFEILIEMIS

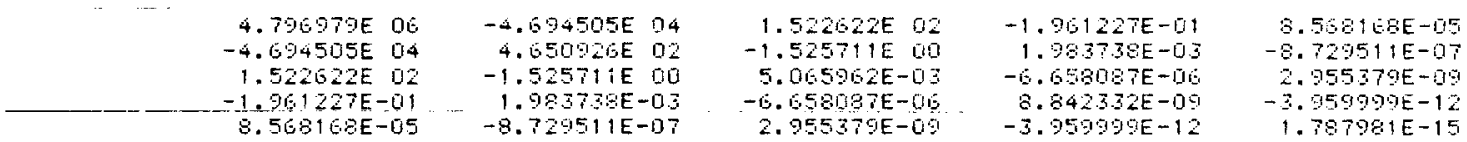

CHECK MATRIX, SHOLLE EE THE IUEMTITY MRTRIX

$\begin{array}{lll}1.000141 E \text { OD } & 2.242575 E-04 & 4.485150 E-04 \\ 2.242575 E-04 & 9.995727 E-01 & 4.350782 E-04 \\ 4.455150 E-04 & 4.358782 E-04 & 1.000793 E-00 \\ 3.787132 E-04 & 4.727763 E-04 & 4.401208 E-04 \\ 2.729575 E-04 & 5.069261 E=04 & 6.342059 E-04\end{array}$

$3.797132 E-014$ 4. $727763 \mathrm{~B}-04$

$4.401305 E-14$

$9.99267 E \mathrm{P}-01$

$4.422417 E-04$

$2.729575 E-04$

5. $1069961 \mathrm{E}-104$

$6.342959 E-04$

$4.422417 \mathrm{E}-04$

1. 0 OONS8E OO

THE OETERMIMANT OF TPE HOFMAL EQUATIOH COEFFICIENTS IS T.444619E-14 $\times 10.0 E-30$

THE NUMEER OF ITERATIONS FOR INUERSION IS 3

Figure 14. Example Application of IBM Program for Measurement of Surface Area of Sintered $\mathrm{UO}_{2}$ Pellet (G-5-C-12) 
COEFFICIENTS DF THE LEAST SQUARES PULYNAMIAL

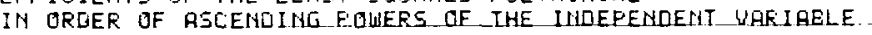

$\begin{array}{cc}\text { COEFFICIENT } & \text { RMS ERROR } \\ -7.896484 E 010 & 5.211515 \mathrm{E}-02 \\ 4.826660 \mathrm{E}-01 & 5.131663 \mathrm{E}-04 \\ -3.134012 \mathrm{E}-04 & 1.693633 \mathrm{E}-06 \\ -5.844049 \mathrm{E}-09 & 2.237545 \mathrm{E}-09 \\ 2.191314 \mathrm{E}-10 & 1.006166 \mathrm{E}-12\end{array}$

THE RMS DEUIATION BETWEEN THE OESERUED FUNCTION AND ITS CALCULATEO AFFROXIMATION IS $1.536 .343 \mathrm{E}-0 \mathrm{~S}$

THE RMS DEUIATION EETWEEN THE TRUE FISHCTION

AND THE DBSERVED FIJHCTION IS $2.379515 \mathrm{E}-05$

COMFUTATIOH OF FRESSURE FRUIA FOTENTIRL MEASUREMENTS

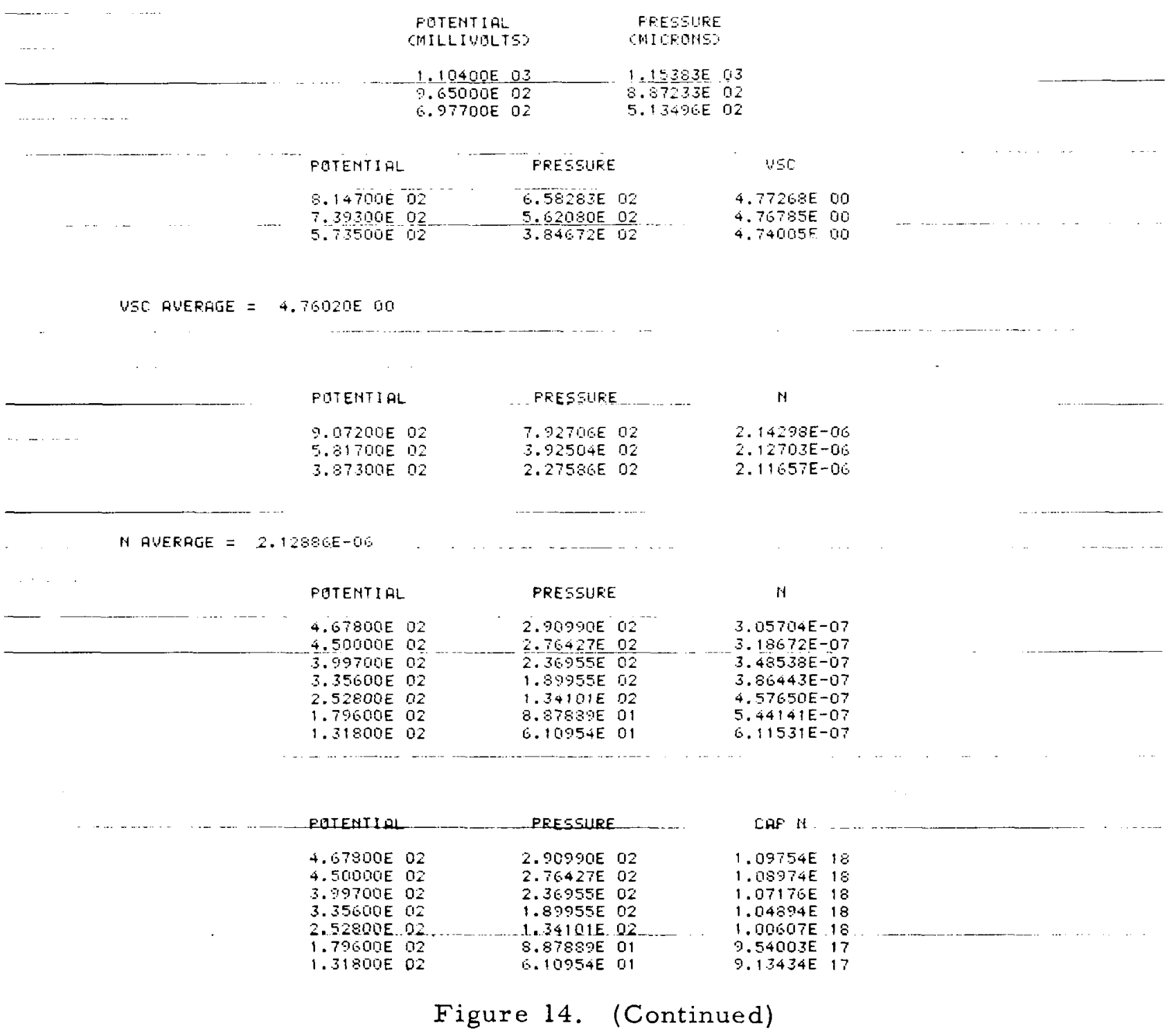

NAA-SR -5319 
PSC CPZRO-PSCDN

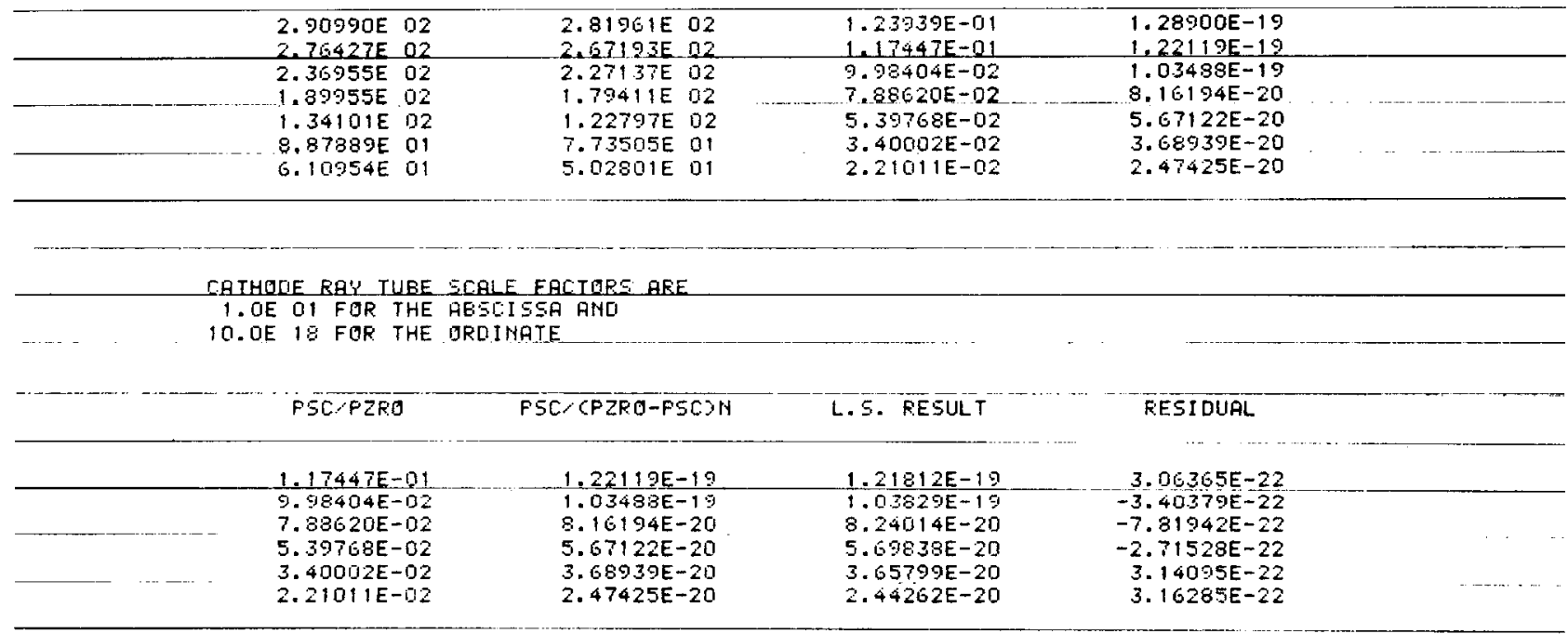

THE SLOPE IS $1.0214 \mathrm{E}-18$ WITH AN PMS ERRTR OF $4.7372 \mathrm{E}-21$

AND IHE INTEFCEPT IS $1.8522 E-21$ WITH AN FMS ERROF: OF $3.9997 E-22$

THE AREA IS $1.8959 E$ OS SQUARE CEHTIMETERS

FHO THE RMS ERROR IS $8.8086 E$ DO

CATHODE EA: TUBE SCALE FACTORS ARE

10.0E-04 FOR THE AESCISSA RHD

10. OE-04 FOR THE DROIHGTE

ESF EXIT 5

Figure 14. (Continued) 


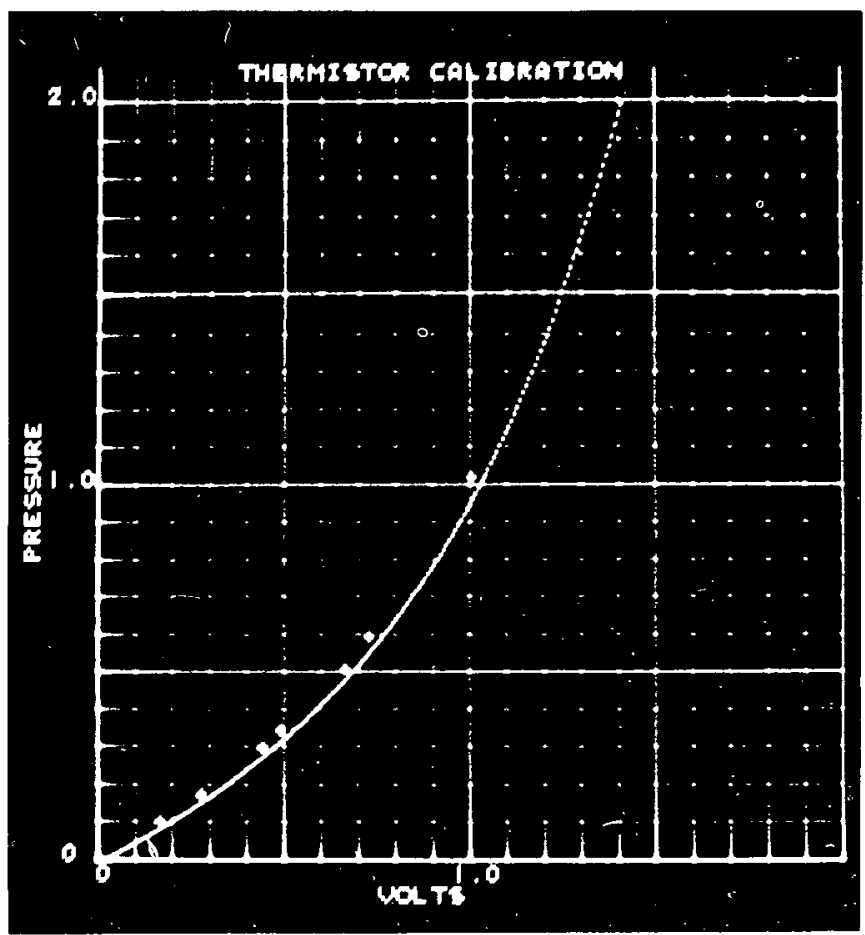

a. Thermistor Calibration

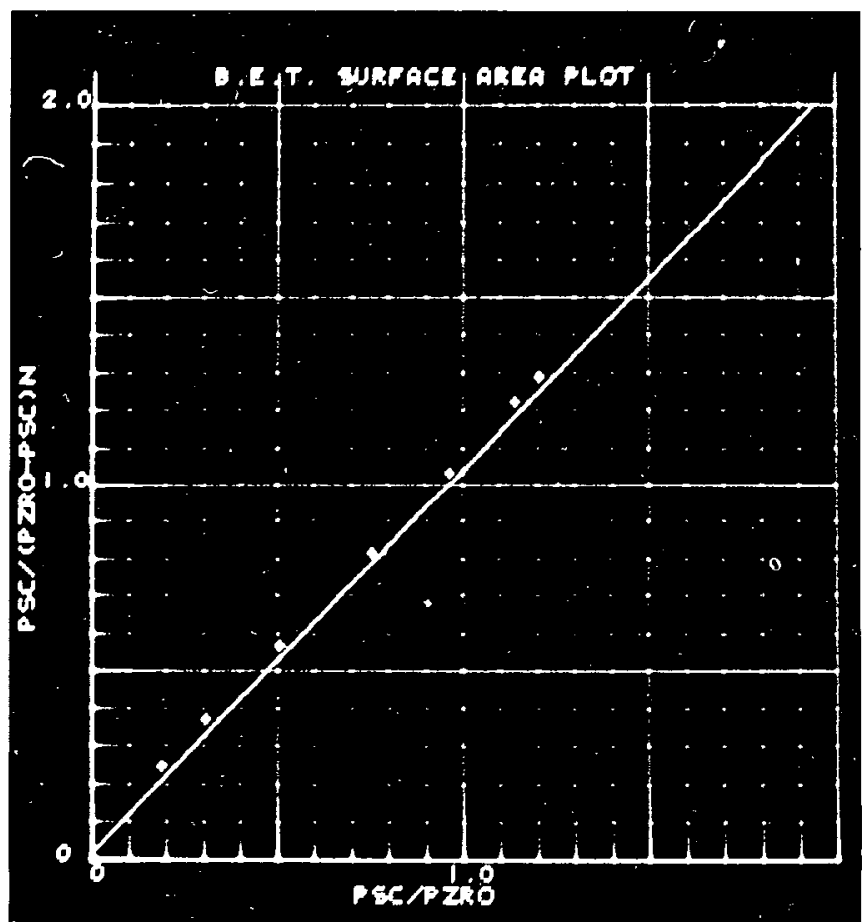

Figure 15. Photographs of Data on Cathode-Ray Tube (The experimental points are on the lines, the plus signs $(+)$ only identify the location of these points) 


\section{REFERENCES}

1. S. Strausberg and T. E. Leuben, NAA-SR-3910 (1959)

2. Metals Research Lab Staff, Carnegie Inst. of Tech., NYO No. 8087 (June 30, 1959)

3. S. Brunauer, P. H. Emmett, and E. Teller, J. Am. Chem. Soc., $\underline{60}$ (1938) p 309

4. L. A. Wooten and C. G. Brown, J. Am. Chem. Soc., 65 (1943) p 113

5. T. N. Rhodin, J. Am. Chem. Soc., $\underline{72}$ (1950) p 5691, 72 (1950) p 4343

6. T. N. Rhodin, J. Phys. Chem., $\underline{57}$ (1953) p 143

7. A. J. Rosenberg, J. Am. Chem. Soc., 78 (1956) p 2929

8. P. H. Emmett, Catalysis Vol. I (New York, Reinhold Publishing Corp, 1954)

9. R. A. Beebe, J. B. Beckwith, and J. M. Honig, J. Am. Chem. Soc., 67 (1945) p 1554

10. R. T. Davis, T. W. DeWitt, and P. H. Emmett, J. Phys. \& Colloid Chem., 51 (1947) p 1232

11. A. Frakas and H. W. Melville, Experimental Methods in Gas Reactions, (London, McMullen Co., Ltd., 1937) p 110

12. J. J. Meihuizen and C. A. Crommelin, Phycica IV, 1 (1937)

13. T. Smith, NAA-SR-4677 (to be published)

14. W. B. Innes, Anal. Chem., 23 (1951) p 759 